OPEN ACCESS

Edited by:

Tzvi Dwolatzky,

Technion Israel Institute of

Technology, Israel

Reviewed by:

Changjiao Sun,

Tsinghua University, China

Daniela Costa,

Universidade NOVA de

Lisboa, Portugal

*Correspondence:

Bin Shen

shenbin_1971@163.com

†These authors have contributed equally to this work and share first

authorship

Specialty section:

This article was submitted to

Geriatric Medicine,

a section of the journal

Frontiers in Medicine

Received: 17 September 2021 Accepted: 08 November 2021

Published: 03 December 2021

Citation:

Peng $L$, Wang $K$, Zeng $Y$, Wu Y, Si $H$ and Shen $B$ (2021) Effect of Neuromuscular Electrical Stimulation After Total Knee Arthroplasty: A

Systematic Review and Meta-Analysis of Randomized Controlled Trials.

Front. Med. 8:779019.

doi: 10.3389/fmed.2021.779019

\section{Effect of Neuromuscular Electrical Stimulation After Total Knee Arthroplasty: A Systematic Review and Meta-Analysis of Randomized Controlled Trials}

\author{
Linbo Peng ${ }^{1 \dagger}$, Kexin Wang ${ }^{2 \dagger}$, Yi Zeng ${ }^{1}$, Yuangang $W^{1}{ }^{1}$, Haibo $\mathrm{Si}^{1}$ and Bin Shen ${ }^{1 *}$ \\ ${ }^{1}$ Department of Orthopedics, Orthopedic Research Institute, West China Hospital, Sichuan University, Chengdu, China, \\ ${ }^{2}$ Department of Clinical Research Management, West China Hospital, Sichuan University, Chengdu, China
}

Background: This systematic review and meta-analysis aimed to evaluate the effect of neuromuscular electrical stimulation (NMES) on quadriceps muscle strength, pain, and function outcomes following total knee arthroplasty (TKA).

Methods: PubMed/Medline, Embase, Web of Science, CENTRAL, Scopus, PsycINFO, PEDro, CINAHL, CNKI, and Wanfang were systematically searched for randomized controlled trials (RCTs) from their inception to 18 June 2021.

Results: Nine RCTs that involving 691 patients were included in the meta-analysis. Our pooled analysis showed that NMES improved quadriceps muscle strength after TKA within 1 months [standardized mean difference (SMD): 0.81; 95\% Cl: 0.51-1.11], 1-2 months (SMD: 0.55; 95\% Cl: 0.13-0.97), 3-4 months (SMD: 0.42; 95\% Cl: 0.18-0.66), and 12-13 months (SMD: 0.46; 95\% Cl: 0.18-0.74), pain between 1 and 2 months [mean difference (MD): $-0.62 ; 95 \% \mathrm{Cl}:-1.04$ to -0.19 ], pain between 3 and 6 months (MD: $-0.44 ; 95 \% \mathrm{Cl}:-0.74$ to -0.14$)$ Western Ontario and McMaster Universities Osteoarthritis Index (WOMAC) between 3 and 4 months (MD: -0.43 ; 95\% Cl: -0.82 to -0.05 ), timed up and go test (TUG) within 1 month (MD: $-2.23 ; 95 \% \mathrm{Cl}:-3.40$ to -1.07), 3 minutes walk test between 3 and 6 months (MD: 28.35; 95\% Cl: 14.55-42.15), and SF-36 MCS between 3 and 6 months after TKA (MD: 4.20, 95\% Cl: 2.41-5.98).

Conclusion: As a supplementary treatment after TKA, postoperative NMES could improve the short-term to long-term quadriceps muscle strength, mid-term pain, and mid-term function following TKA. However, many outcomes failed to achieve statistically meaningful changes and minimal clinically important difference (MCID), thus the clinical benefits remained to be confirmed.

Level of Evidence: Therapeutic level I.

Systematic Review Registration: https://www.crd.york.ac.uk/PROSPERO/, identifier CRD42021265609.

Keywords: total knee arthroplasty, neuromuscular electrical stimulation, quadriceps muscle strength, pain, function, systematic review, meta-analysis 
What is Known: Neuromuscular electrical stimulation was regarded as a potential approach to improve muscle contractility and postoperative quadriceps weakness. With relevant studies published, the advantage of NMES on quadriceps muscle strength, pain, and function outcomes following TKA remains controversial.

What is New: This systematic review and meta-analysis is the first to identify that postoperative NMES could improve the quadriceps muscle strength, pain, and function following the TKA surgery. The quality of evidence ranged from good to high. However, many outcomes failed to achieve statistically meaningful changes and MCID, thus the clinical benefits remained to be confirmed.

\section{INTRODUCTION}

Total knee arthroplasty (TKA) is one of the most common and cost-effective procedures for patients with end-stage osteoarthritis of the knee, which has been performed with increasing frequency in recent years $(1,2)$. Although TKA provides patients with reduced pain and a functional range of motion (ROM) of the knee joint, quadriceps strength impairment is common following the surgery (3). Besides, almost all patients suffer from postoperative pain with different levels, which affect postoperative satisfaction and outcomes (4). Studies have shown that nearly $20 \%$ of primary TKA patients were not satisfied with their outcomes following the surgery (5).

Standardized physical therapy and pharmacologic analgesia improve muscle strength and pain after TKA (6). However, the content of rehabilitation varies worldwide $(7,8)$. Electrical stimulation is effective in accelerating recovery from surgery (9). Neuromuscular electrical stimulation (NMES) has been utilized since the eighteenth century (10). It was regarded as a potential approach to improve muscle contractility and postoperative quadriceps weakness (11). A systematic review involving a total of 933 participants found that NMES may be an effective treatment for muscle weakness and should be regarded as a crucial part of rehabilitation programs (12). The advantages of NMES have been emphasized in many diseases such as anterior cruciate ligament injury, neck pain, stroke, and cerebral palsy (13-17).

Recently, some studies have examined the effect of NMES following TKA but remain controversial (18-23). The clinical effectiveness of NMES following TKA on quadriceps muscle

\footnotetext{
Abbreviations: NMES, neuromuscular electrical stimulation; TKA, total knee arthroplasty; PRISMA, preferred reporting items for systematic reviews and metaanalyses; ROM, range of motion; RCT, randomized controlled trial; MCS, mental component score; PCS, physical component score; SF-36, 36-item short form health survey; CENTRAL, Cochrane central register of controlled trials; CNKI, China national knowledge infrastructure; PCI, physiological cost index; VAS, visual analog scale; NPRS, numerical pain rating scale; WOMAC, western ontario and momaster universities osteoarthritis index; TUG, timed up and go test; SCT, stair climbing test; $3 \mathrm{MWT}, 3$ minutes walk test; $6 \mathrm{MWT}, 6$ minutes walk test; MD, mean difference; SMD, standardized mean difference; MVIC, maximal voluntary isometric contraction; BMI, body mass index; mNMES, motor-level NMES; sNMES, sensory-level NMES; KOS ADLS, knee outcome survey activities of daily living scale; HRQoL, health-related quality-of-life; MCID, minimal clinically important difference.
}

strength, pain, and function outcomes remains unclear. We conduct this meta-analysis to evaluate the effect of NMES on quadriceps muscle strength, pain, and function outcomes following TKA further.

\section{METHODS}

This study was based on the previous published RCTs. Thus, the ethical approval and consent to participate were not necessary. This systematic review and meta-analysis is performed following the Cochrane Handbook for Systematic Reviews of Interventions (24) and Preferred Reporting Items for Systematic Reviews and Meta-Analyses (PRISMA) guidelines (25). The protocol was registered in the PROSPERO (Registration number: CRD42021265609).

\section{Search Strategy}

The PubMed/Medline, Embase, Web of Science, the Cochrane Central Register of Controlled Trials (CENTRAL), Scopus, PsycINFO, Physiotherapy Evidence Database (PEDro), CINAHL, China National Knowledge Infrastructure (CNKI), and Wanfang (a Chinese database) were systematically searched for randomized controlled trials (RCTs) from their inception to 18 June 2021 by two independent reviewers (LBP and KXW). The search strategies were shown in Appendix 1.

\section{Eligibility Criteria}

The studies included in the meta-analysis were required to meet the following inclusion criteria: (1) Patients: adult patients undergoing primary TKA; (2) Intervention: postoperative NMES. NMES was utilized in the intervention group after the TKA surgery. Patients who received preoperative NMES were excluded; (3) Comparison: conventional rehabilitation or conventional physical therapy. Patients who received any form of electrical stimulation in the control group were excluded; (4) Outcomes: The primary outcome measures, such as quadriceps muscle strength [maximal volitional isometric contraction (MVIC)], physiological cost index (PCI), pain such as visual analog scale (VAS), and numerical pain rating scale (NPRS), Western Ontario and McMaster Universities Osteoarthritis Index (WOMAC), Timed Up and Go Test (TUG), Stair-Climbing Test (SCT), 3 Minutes Walk Test (3MWT), 6 Minutes Walk Test (6MWT), range of motion (ROM), and 36-Item Short-Form Health Survey (SF-36); (5) Study design: randomized controlled trials (RCTs); language and published time restrictions were not employed.

Maximal volitional isometric contraction is a classic method to calculate muscle strength for patients with neuromuscular disorders by providing intrinsic factors such as units of kilograms and Newtons of force (26). As a measure of energy cost, PCI was calculated by dividing the heart rate increase (heart rate at the end of the $3 \mathrm{MWT}$ minus resting heart rate) by walking speed $(\mathrm{m} / \mathrm{min})(18,21)$. A lower PCI score indicated a lower energy cost during walking (27). To assess the TUG score, patients were asked to rise from an armchair, walk $3 \mathrm{~m}$ away, then turn and walk back to sit down on the same chair $(28,29)$. The TUG is an excellent representation of essential mobility, 
strength, balance, and agility (29). The SCT was used to assess the lower extremity strength, power, and balance (29). The 3MWT is a simple, non-incremental, and easy to conduct submaximal strength test (30). As a standard walking test, 6MWT has been widely used to determine the progress following rehabilitation intervention (31). The SF-36 is the most widely used healthrelated quality-of-life (HRQoL) in the USA (32). The SF-36 is consists of eight individual subscales. Scores of those subscales can be combined into two higher-order summary scores: PCS and MCS (33).

\section{Identification of studies via databases and registers}

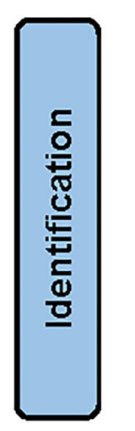

\begin{tabular}{|c|c|}
\hline $\begin{array}{l}\text { Records identified from databases } \\
\text { ( } n=761) \text { : } \\
\text { PubMed/Medline }(n=96), \text { Embase } \\
(n=65), \text { Web of Science }(n=92), \\
\text { CENTRAL }(n=133), \text { Scopus }(n \\
=152), \text { PsycINFO }(n=46), \text { PEDro }(n \\
=14), \text { CINAHL }(n=65), \text { CNKI }(n= \\
57) \text { and Wanfang }(n=41)\end{array}$ & $\begin{array}{l}\text { Records removed before } \\
\text { screening: } \\
\text { Duplicate records removed } \\
\text { ( } n=344) \\
\text { Records marked as ineligible } \\
\text { by automation tools }(n=242) \\
\text { Records removed for other } \\
\text { reasons }(n=102)\end{array}$ \\
\hline
\end{tabular}
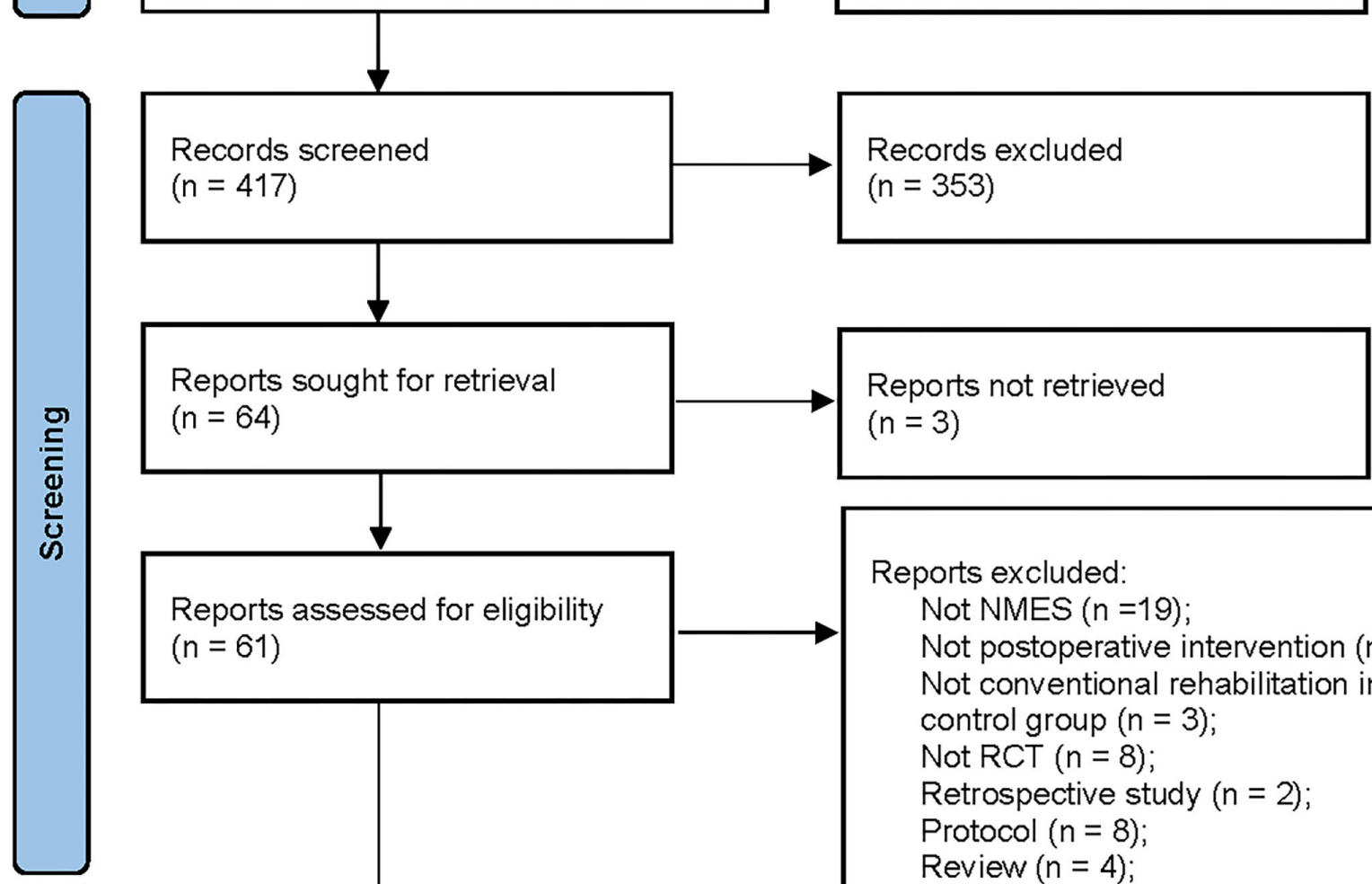

Reports excluded:

Not NMES $(n=19)$;

Not postoperative intervention $(n=3)$;

Not conventional rehabilitation in the control group $(n=3)$;

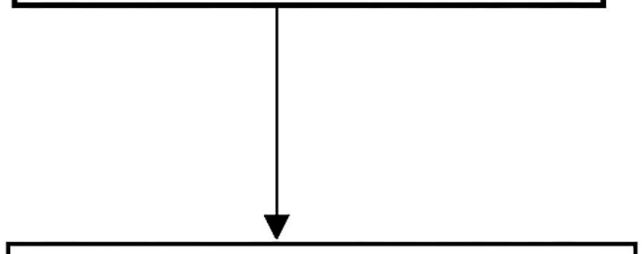

Not RCT $(n=8)$;

Retrospective study $(n=2)$;

Protocol $(n=8)$;

Review $(n=4)$;

Not TKA $(n=2)$;

Outcomes not related $(n=3)$

Studies included in review

$(n=9)$

Studies included in meta-analysis

$(n=9)$

FIGURE 1 | Flow chart of studies selection according to preferred reporting items for systematic reviews and meta-analyses guidelines. EMBASE, Excerpta Medica Database; CENTRAL, Cochrane Central Register of Controlled Trials; PEDro, Physiotherapy Evidence Database; CNKI, China National Knowledge Infrastructure; TKA, Total Knee Arthroplasty; NMES, Neuromuscular electrical stimulation; RCT, Randomized Controlled Trial. 
TABLE 1 | Characteristics of studies included in the meta-analysis.

\begin{tabular}{|c|c|c|c|c|c|c|c|}
\hline $\begin{array}{l}\text { Author(s)/year/ } \\
\text { country/design }\end{array}$ & $\begin{array}{l}\text { Patients (I: C); } \\
\text { female } \\
\text { proportion (I: C) }\end{array}$ & Age (l: C) & BMI (I: C) & $\begin{array}{l}\text { Intervention vs. } \\
\text { control }\end{array}$ & $\begin{array}{l}\text { Intervention frequency, duration, and } \\
\text { time }\end{array}$ & $\begin{array}{l}\text { Intervention } \\
\text { intensity }\end{array}$ & Main outcome measures \\
\hline $\begin{array}{l}\text { Avramidis et al. } \\
\text { /2003/UK/2-arm } \\
\text { RCT }\end{array}$ & $\begin{array}{l}\text { 15(I):15(C); } \\
\text { 10/15(l):12/15(C) }\end{array}$ & $\begin{array}{l}68.20 \pm 10.59(1): \\
71.20 \pm 7.83(C)\end{array}$ & Not mentioned & $\begin{array}{l}\text { NMES+ } \\
\text { conventional PT } \\
\text { vs. Conventional } \\
\text { PT }\end{array}$ & $\begin{array}{l}\text { NMES }(40 \mathrm{~Hz}, 300 \mu \mathrm{s}) \text { of the vastus } \\
\text { medialis for } 2 \mathrm{~h} \text { on each occasion, twice } \\
\text { daily, from the second day postoperative } \\
\text { to the } 6 \text { weeks postoperative }\end{array}$ & $\begin{array}{l}\text { Maximum } \\
\text { tolerable intensity }\end{array}$ & $3 \mathrm{MWT}, \mathrm{PCl}, \mathrm{HSS}$ at 6,12 weeks postoperatively \\
\hline $\begin{array}{l}\text { Petterson et } \\
\text { al./2009/US/2-arm } \\
\text { RCT }\end{array}$ & $\begin{array}{l}\text { 100(I): 100(C); } \\
\text { 47/100(I): } \\
\text { 45/100(C) }\end{array}$ & $\begin{array}{l}65.3 \pm 8.3(l): 65.2 \\
\pm 8.5(C)\end{array}$ & $\begin{array}{l}29.67 \pm 4.85(I): \\
29.99 \pm 3.90(C)\end{array}$ & $\begin{array}{l}\text { NMES+ exercise } \\
\text { vs. Exercise }\end{array}$ & $\begin{array}{l}\text { NMES } 2 \text { or } 3 \text { times per week for } 6 \text { weeks } \\
\text { with a minimum requirement of } 12 \text { therapy } \\
\text { visits }\end{array}$ & $\begin{array}{l}\text { Maximum } \\
\text { tolerable intensity }\end{array}$ & $\begin{array}{l}\text { SF-36 (PCS, MCS), KOS-ADLS, pain-KOS, TUG, } \\
\text { SCT, 6MWT, active flexion ROM, active extension } \\
\text { ROM and CAR (NMVIC, newtons/BMI) at } 3,12 \\
\text { months postoperatively }\end{array}$ \\
\hline $\begin{array}{l}\text { Valdés et } \\
\text { al./2010/Spain/2- } \\
\text { arm } \\
\text { RCT }\end{array}$ & $\begin{array}{l}39(1): 44(C) ; \\
\text { 25/39(I): 25/44(C) }\end{array}$ & $\begin{array}{l}72 \pm 6(1): 70 \pm \\
7(C)\end{array}$ & $\begin{array}{l}32.3 \pm 4.7(1): 32.4 \\
\pm 6.3(C)\end{array}$ & $\begin{array}{l}\text { NMES+ standard } \\
\text { rehabilitation vs. } \\
\text { Standard } \\
\text { rehabilitation }\end{array}$ & $\begin{array}{l}\text { NMES ( } 65 \mathrm{~Hz}, 300 \mu \mathrm{s}, 15-30 \mathrm{~mA} \text { ) of } \\
\text { feedback to the quadriceps for } 15 \mathrm{~min} \\
\text { once a day from the day after surgery }\end{array}$ & Not mentioned & $\begin{array}{l}\text { BA, TUG, WOMAC pain, WOMAC stiffness, } \\
\text { WOMAC function at } 1,3 \text { months; LOS }\end{array}$ \\
\hline $\begin{array}{l}\text { Avramidis et al. } \\
\text { /2011/Greece/2- } \\
\text { arm } \\
\text { RCT }\end{array}$ & $\begin{array}{l}\text { 35(I): 35(C); } \\
\text { 28/35(I): 29/35(C) }\end{array}$ & $\begin{array}{l}70.54 \pm 4.68(l): \\
70.66 \pm 3.73(\mathrm{C})\end{array}$ & $\begin{array}{l}27.38 \pm 2.65(l): \\
27.14 \pm 3.31(C)\end{array}$ & $\begin{array}{l}\text { NMES+ } \\
\text { conventional } \\
\text { physiotherapy vs. } \\
\text { Conventional } \\
\text { physiotherapy }\end{array}$ & $\begin{array}{l}\text { NMES ( } 40 \mathrm{~Hz}, 300 \mu \mathrm{s}) \text { of the vastus } \\
\text { medialis muscle twice daily for } 2 \mathrm{~h} \text { from the } \\
\text { second postoperative day }\end{array}$ & $\begin{array}{l}\text { Maximum } \\
\text { tolerable intensity }\end{array}$ & $\begin{array}{l}\text { AKSS, OKS, SF-36, 3MWT, PCl at 6, 12, and } 52 \\
\text { weeks postoperatively }\end{array}$ \\
\hline $\begin{array}{l}\text { Stevens-Lapsley } \\
\text { et } \\
\text { al./2012/US/2-arm } \\
\text { RCT }\end{array}$ & $\begin{array}{l}35(I): 31(C) ; \\
20 / 35(I): 16 / 31(C)\end{array}$ & $\begin{array}{l}66.2 \pm 9.1(1): 64.8 \\
\pm 7.7(C)\end{array}$ & $\begin{array}{l}27.1 \pm 4.9(1): 31.2 \\
\pm 4.2(C)\end{array}$ & $\begin{array}{l}\text { NMES+ standard } \\
\text { rehabilitation vs. } \\
\text { Standard } \\
\text { rehabilitation }\end{array}$ & $\begin{array}{l}\text { NMES ( } 600 \mu \mathrm{s}) \text { twice daily from } 2 \text { days } \\
\text { after surgery }\end{array}$ & $\begin{array}{l}\text { Maximum } \\
\text { tolerable intensity }\end{array}$ & $\begin{array}{l}\text { Quadriceps and hamstring muscle strength, TUG, } \\
\text { SCT, 6MWT, NPRS, active flexion ROM, active } \\
\text { extension ROM, SF- } 36 \text { (PCS, MCS), WOMAC, GRS } \\
\text { at } 3.5,6.5,13,26,52 \text { weeks postoperatively }\end{array}$ \\
\hline $\begin{array}{l}\text { Levine et } \\
\text { al./2013/US/2-arm } \\
\text { RCT }\end{array}$ & $\begin{array}{l}35(I): 35(C) ; \\
25 / 35(I): 21 / 35(C)\end{array}$ & $68.1(\mathrm{I}): 65.1(\mathrm{C})$ & $30.6(l): 31.9(C)$ & $\begin{array}{l}\text { NMES+ ROM } \\
\text { exercise vs. } \\
\text { therapist- } \\
\text { managed } \\
\text { PT }\end{array}$ & $\begin{array}{l}\text { NMES used from the second day } \\
\text { postoperatively }\end{array}$ & Not mentioned & $\begin{array}{l}\text { KSS pain, KSS function, WOMAC, passive flexion } \\
\text { ROM, passive extension ROM, TUG at } 6 \text { weeks and } \\
6 \text { months postoperatively }\end{array}$ \\
\hline $\begin{array}{l}\text { Demet et } \\
\text { al./2015/Turkey/2- } \\
\text { arm } \\
\text { RCT }\end{array}$ & $\begin{array}{l}30(I): 30(C) ; \\
28 / 30(I): 29 / 30(C)\end{array}$ & $\begin{array}{l}66.2 \pm 7.2(1): 64.6 \\
\pm 6.6(C)\end{array}$ & $\begin{array}{l}29.1 \pm 3.9(1): 30.1 \\
\pm 4.6(C)\end{array}$ & $\begin{array}{l}\text { NMES+ exercise } \\
\text { vs. Exercise }\end{array}$ & $\begin{array}{l}\text { NMES }(30-100 \mathrm{~Hz}, 400 \mu \mathrm{s}, 28-90 \mathrm{~mA}) \text { of } \\
\text { the vastus medialis muscle for } 30 \mathrm{~min}, 5 \\
\text { days a week from the first day } \\
\text { postoperatively. }\end{array}$ & $\begin{array}{l}\text { Maximum } \\
\text { tolerable intensity }\end{array}$ & $\begin{array}{l}\text { flexion ROM, extension ROM, TUG, WOMAC, } \\
\text { SF-36, VAS at 1, } 3 \text { months postoperatively }\end{array}$ \\
\hline $\begin{array}{l}\text { Yoshida et } \\
\text { al./2017/Japan/3- } \\
\text { arm } \\
\text { RCT }\end{array}$ & $\begin{array}{l}22 \text { (sNMES): } 22 \\
\text { (mNMES): } 22 \\
\text { (Control); } 18 / 22 \\
\text { (sNMES): } 18 / 22 \\
\text { (mNMES): } 20 / 22 \\
\text { (Control) }\end{array}$ & $\begin{array}{l}71.6 \pm 7.0 \\
\text { (sNMES):75.9 } \\
4.7 \text { (mNMES): } 72.5 \\
\pm 6.2 \text { (Control) }\end{array}$ & $\begin{array}{l}25.4 \pm 2.2 \\
\text { (sNMES): } 24.6 \pm \\
2.9 \text { (mNMES): } \\
25.8 \pm 3.3 \\
\text { (Control) }\end{array}$ & $\begin{array}{l}\text { sNMES+ standard } \\
\text { rehabilitation vs. } \\
\text { mNMES+ } \\
\text { standard } \\
\text { rehabilitation vs. } \\
\text { Standard } \\
\text { rehabilitation }\end{array}$ & $\begin{array}{l}\text { sNMES }(100 \mathrm{~Hz}, 1 \mathrm{~ms}, 10-15 \mathrm{~mA}, 45 \\
\mathrm{min} / \text { day) and mNMES }(100 \mathrm{~Hz}, 1 \mathrm{~ms} \text {, } \\
15-38 \mathrm{~mA}, 45 \mathrm{~min} / \text { day) } 5 \text { days/week for } 2 \\
\text { weeks from the second weeks } \\
\text { postoperatively }\end{array}$ & $\begin{array}{l}\text { Sensory-level } \\
\text { intensity (sNMES) } \\
\text { and maximum } \\
\text { tolerable intensity } \\
\text { (mNMES) }\end{array}$ & $\begin{array}{l}\text { MVIC, LSMM, TUG, } 2 M W T \text {, VAS }(0-100 \mathrm{~mm}) \text {, } \\
\text { passive flexion ROM and passive extension ROM at } \\
2 \text { weeks postoperatively }\end{array}$ \\
\hline $\begin{array}{l}\text { Klika et } \\
\text { al./2020/US/2-arm } \\
\text { RCT }\end{array}$ & $\begin{array}{l}\text { 24(I): 22(C); } \\
\text { 18/24(I): 17/22(C) }\end{array}$ & $\begin{array}{l}65 \pm 5.8(1): 65 \pm \\
7.6(C)\end{array}$ & Not mentioned & $\begin{array}{l}\text { NMES+ standard } \\
\text { PT vs. Standard } \\
\text { PT }\end{array}$ & $\begin{array}{l}\text { NMES ( } 15-85 \mathrm{~V}, 50 \mathrm{pps}, 5 \mathrm{~ms}) \text { for } 200 \\
\mathrm{~min} / \text { week, } 12 \text { weeks from the day of } \\
\text { surgery }\end{array}$ & $\begin{array}{l}\text { Maximum } \\
\text { tolerable intensity }\end{array}$ & $\begin{array}{l}\text { Quadriceps strength, ROM, resting pain, TUG, SCT, } \\
\text { KOOS and VR-12 at 3, 6, and } 12 \text { weeks } \\
\text { postoperatively }\end{array}$ \\
\hline
\end{tabular}

I, Intervention; C, Control; BMI, body mass index; RCT, randomized controlled trial; NMES, neuromuscular electrical stimulation; PT, physical therapy; 3MWT, 3-minute walking test; PCI, hysiological Cost Index; HSS, Hospital for Special Surgery knee score; ROM, range of motion; TUG, timed up and go test; 6MWT, 6-minute walk test: MVIC, normalized maximal volitional isometric contraction; CAR, the central activation ratio; BMI, body mass index; SCT, stair climbing test; SF-36, Short Form 36; PCS, physical component score; MCS, mental component score; KOS ADLS, Knee Outcome Survey Activities of Daily Living scale; BA, balance articular; WOMAC, Western Ontario and MCMaster Universities Osteoarthritis Index; LOS, length of stay; AKSS, American Knee Society clinical score; OKS, Oxford knee score; NPRS, Numeric Pain Rating Scale; GRS, global rating scale; KSS, knee Society score; VAS, visual analogue scale; sNMES, sensory-level neuromuscular electrical stimulation; mNMES, motor- level neuromuscular electrical stimulation; LSMM; leg skeletal muscle mass; 2MWT, 2-minute walk test; KOOS, Knee injury and Osteoarthritis Outcome Score; VR-12, veterans rand-12. 


\section{Study Selection}

Firstly, all the identified studies were imported into the Endnote X9 (Thomson Reuters, CA, USA). After removing the duplicate studies, two reviewers (YGW and HBS) scanned the titles, abstracts, and full texts independently. Any disagreements were resolved by discussion with a senior reviewer (YZ). Commentaries, letters, case reports, trial protocols, reviews, and retrospective studies were excluded from our systematic review and meta-analysis.

\section{Data Extraction}

Two authors (LBP and YGW) extracted the following data independently and discussed with a senior reviewer (HBS) if disagreements existed. The extracted data including the publication data (the name of the author; publication year; country; study design), demographic characteristics [number of patients, age, sex, body mass index (BMI)], characteristics of the intervention (frequency, duration, intensity of the NMES program), rehabilitation type of the control group, outcomes data (quadriceps muscle strength, PCI, VAS, NPRS, WOMAC, TUG, SCT, 3MWT, 6MWT, ROM, and SF-36).

\section{Study Quality Assessment}

Two authors (KXW and YZ) evaluated the methodological quality of the included studies independently with the Cochrane bias risk assessment tool and discussed with a senior reviewer (BS) if any disagreements existed (34). Each study was documented with low, high, or unclear risk of bias in each domain.

\section{Statistical Analysis}

The review manager software (RevMan 5.3, Oxford, United Kingdom) was used to conduct our meta-analysis and produce forest plots. All the continuous variable outcomes were presented as the mean difference (MD) with a 95\% CI to calculate the total effect of NMES on patients following TKA. The standardized mean difference (SMD) was used to calculate the total effect if different scales were utilized among the studies (35). $I^{2}$ statistics measured heterogeneity among the studies. The random-effects model was used if substantial heterogeneity exists $\left(P<0.05\right.$ or $\left.I^{2}>50 \%\right)$. If not, the fixed-effects model was adopted. A $P<0.05$ demonstrated a statistically significant difference.

\section{RESULTS}

\section{Study Selection}

A total of 761 studies were identified from the initial search. After removing 344 records for duplicates, 353 studies were excluded by screening the title and abstract. After excluding three studies for not being retrieved, the remaining 61 studies were screened the full-text for eligibility. Fifty-two reports were excluded by screening the full-text: not NMES $(n=19)$; not postoperative intervention $(n=3)$; not conventional rehabilitation in the control group $(n=3)$; not RCT $(n=8)$; retrospective study ( $n$ $=2)$; protocol $(n=8)$; review $(n=4)$; not TKA $(n=2)$; and outcomes not related $(n=3)$. The remaining nine RCTs involving 691 patients met the eligibility criteria and were included in the meta-analysis $(18,19,21,22,36-40)$. The PRISMA flow diagram was shown in Figure 1.

\section{Study Characteristics}

Among all the included studies, eight were 2-arm RCTs (18, 19, 21, 22, 36-38, 40) and one was 3-arm RCTs (39). The average sample size was 77 patients (ranging from 30 to 200). The follow-up periods of each article ranged from 4 to 52 weeks. Three hundred and fifty-seven patients received NMES therapy following TKA surgery, while 334 received conventional rehabilitation therapy. The included trials were performed in different countries: one in the UK (18), four in the USA $(19,22$,

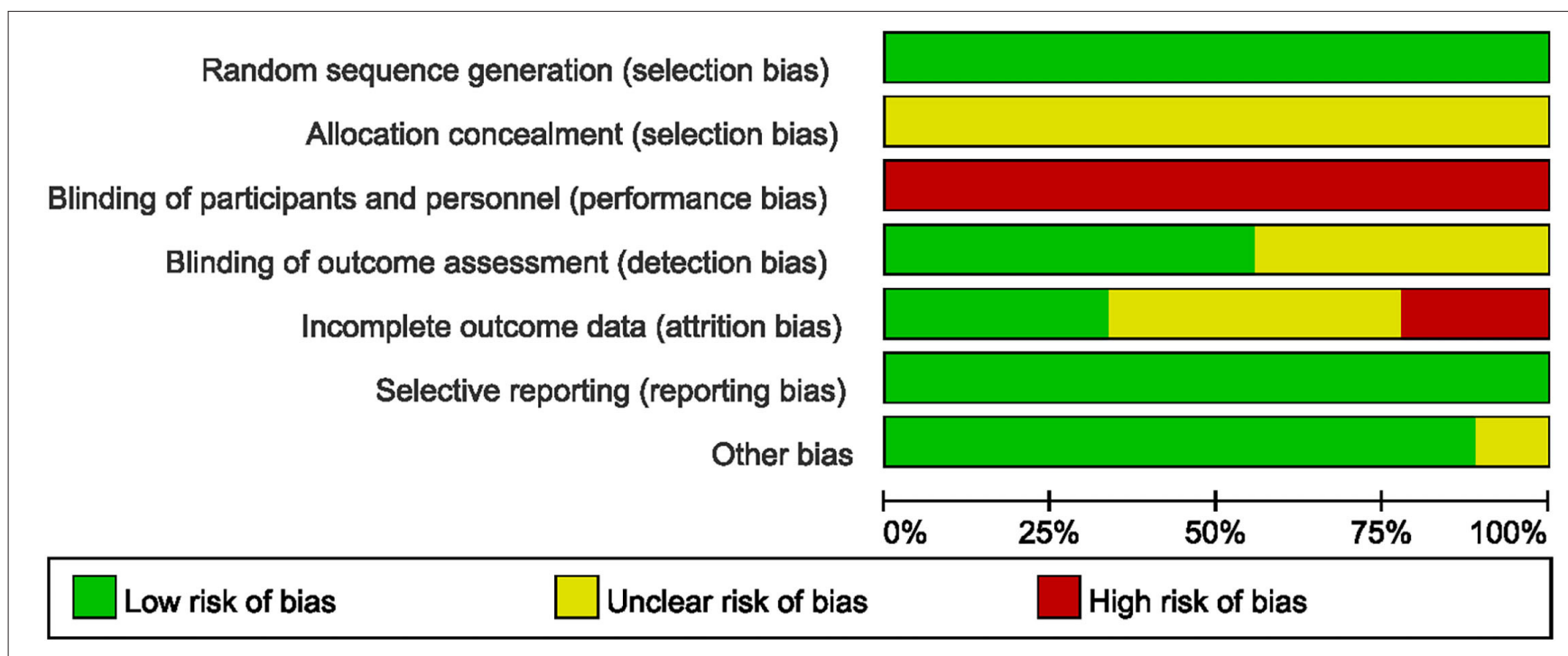

FIGURE 2 | Risk of bias graph across all included studies. 


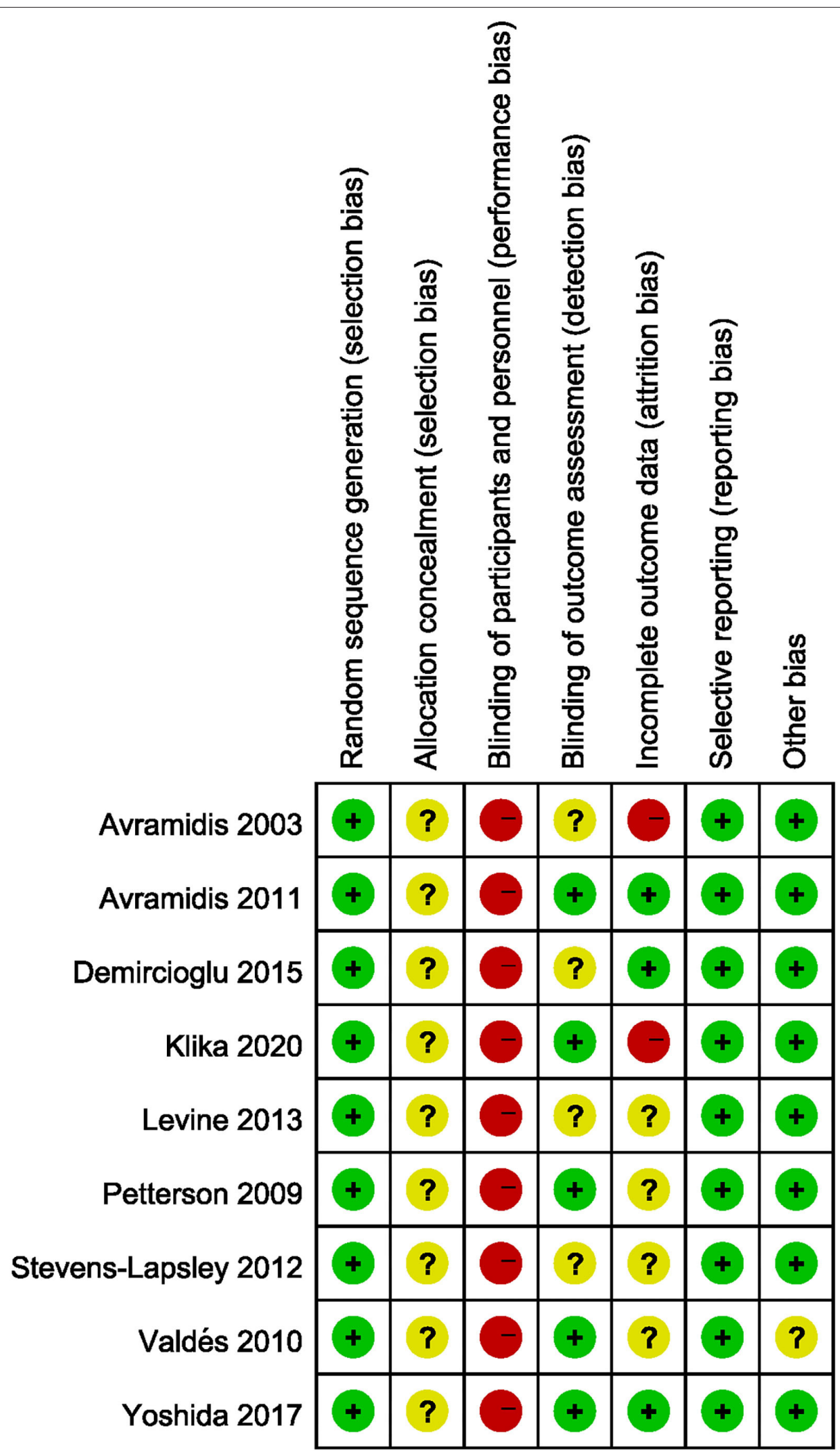




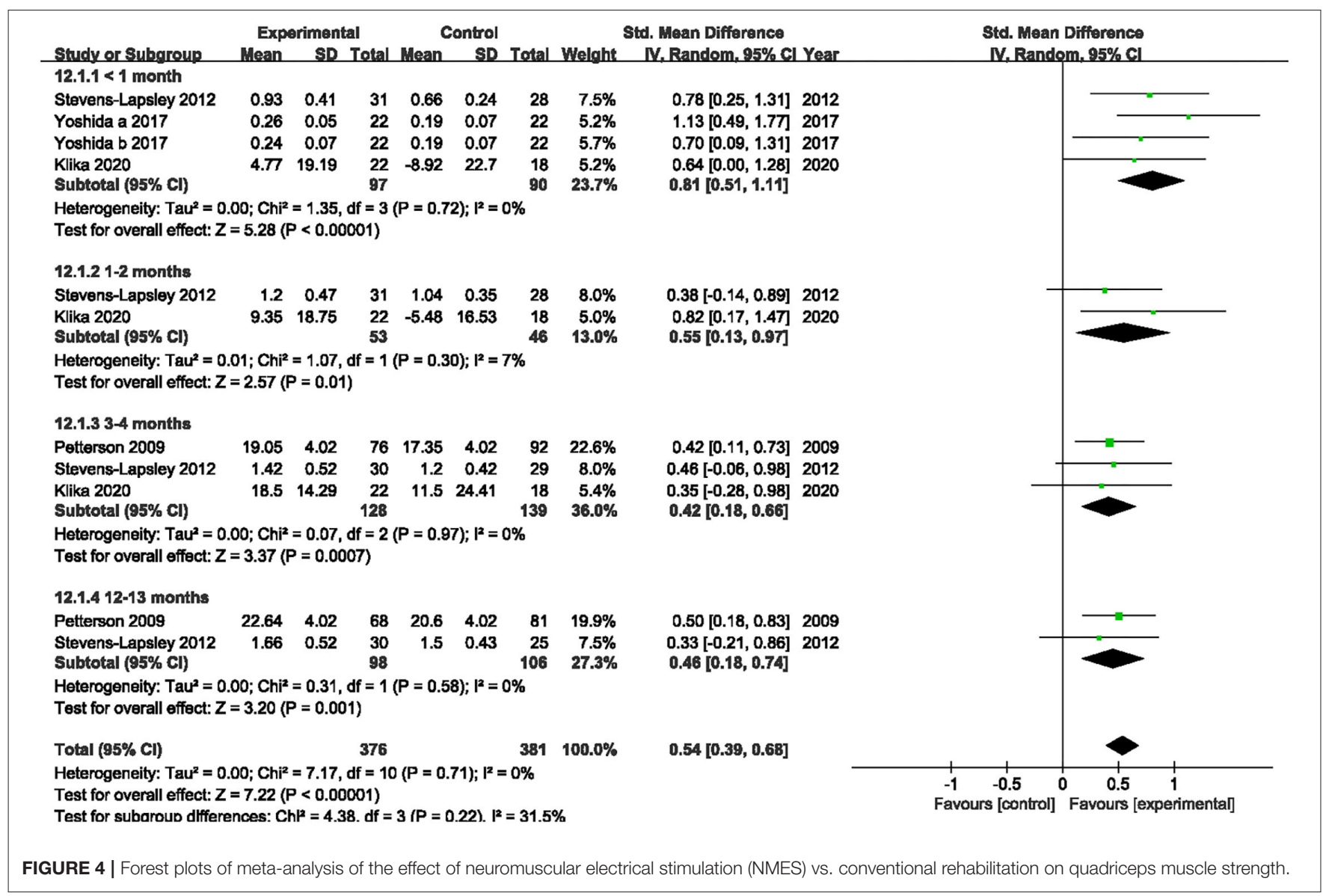

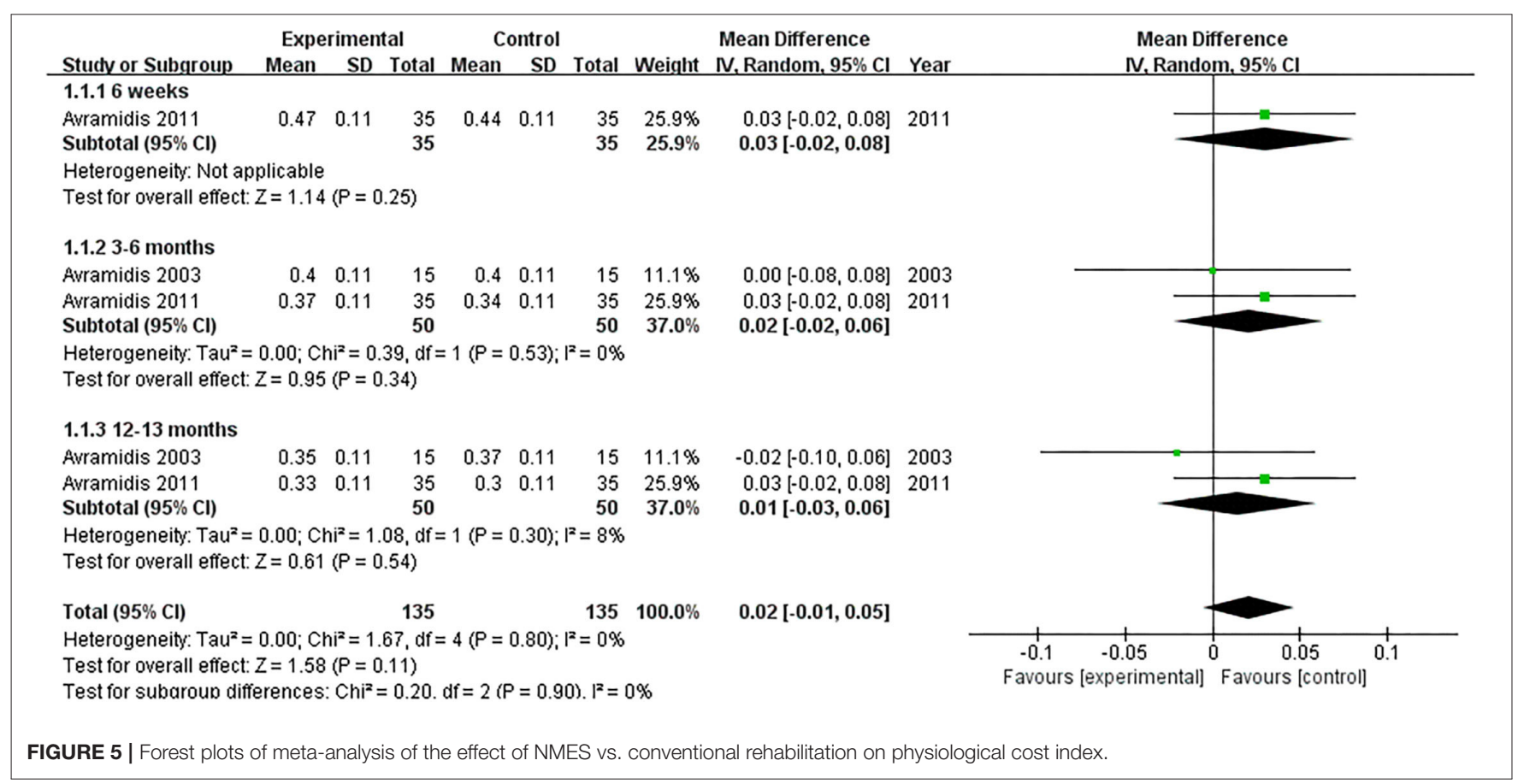


37, 40), one in Spain (36), one in Greece (21), one in Turkey (38), and one in Japan (39). All the characteristics of included studies were presented in Table 1.

\section{Interventions}

All the involved patients received similar conventional rehabilitation/physical therapy/exercise. Besides, patients in the NMES groups received similar NMES therapy in all the included nine RCTs. The frequency of NMES ranged from 30 to $100 \mathrm{~Hz}$, and the duration ranged from $300 \mu \mathrm{s}$ to $1 \mathrm{~ms}$ in six studies $(18,21,22,36,38,39)$. Klika et al. set the frequency as 50 pps and the pulse width as $5 \mathrm{~ms}$ (40). Two studies did not document the frequency and duration data of the NMES protocol $(19,37)$. Three RCTs reported that the NMES therapy was used twice daily $(18,21,22)$. Petterson et al. (19) conducted NMES therapy 2 or 3 times per week in the experimental group, while the other two pieces of literature $(38,39)$ utilized it 5 days per week. Valdés et al. adopted the NMES for 15 min once a day began from the day after surgery (36). NMES was conducted in the research of Klika et al. for 200 min per week (40). Seven studies utilized the NMES with maximum tolerable intensity
$(18,19,21,22,38-40)$. The other two RCTs did not report the intensity data of NMES $(36,37)$. The intervention characteristics were shown in Table 1.

\section{Study Quality Assessment}

The risk of bias of all the included studies varied substantially. Allocation concealment bias was unclear in all nine studies (18, $19,21,22,36-40)$. All the studies failed to achieve performance bias $(18,19,21,22,36-40)$. Five RCTs implied the blinded assessors in their studies $(19,21,36,39,40)$. The risk of bias graph for each study and the risk of bias summary was shown in Figures 2, 3.

\section{Outcomes}

\section{Quadriceps Muscle Strength}

Four studies reported the quadriceps muscle strength $(19,22,39$, 40). Since the included studies adopt different intrinsic factors to normalize MVIC values, the SMD was used to calculate the total effect of quadriceps muscle strength. Our pooled analysis involving four studies indicated that NMES improved MVIC after TKA within 1 month (SMD: 0.81; 95\% CI: 0.51-1.11, $P<$

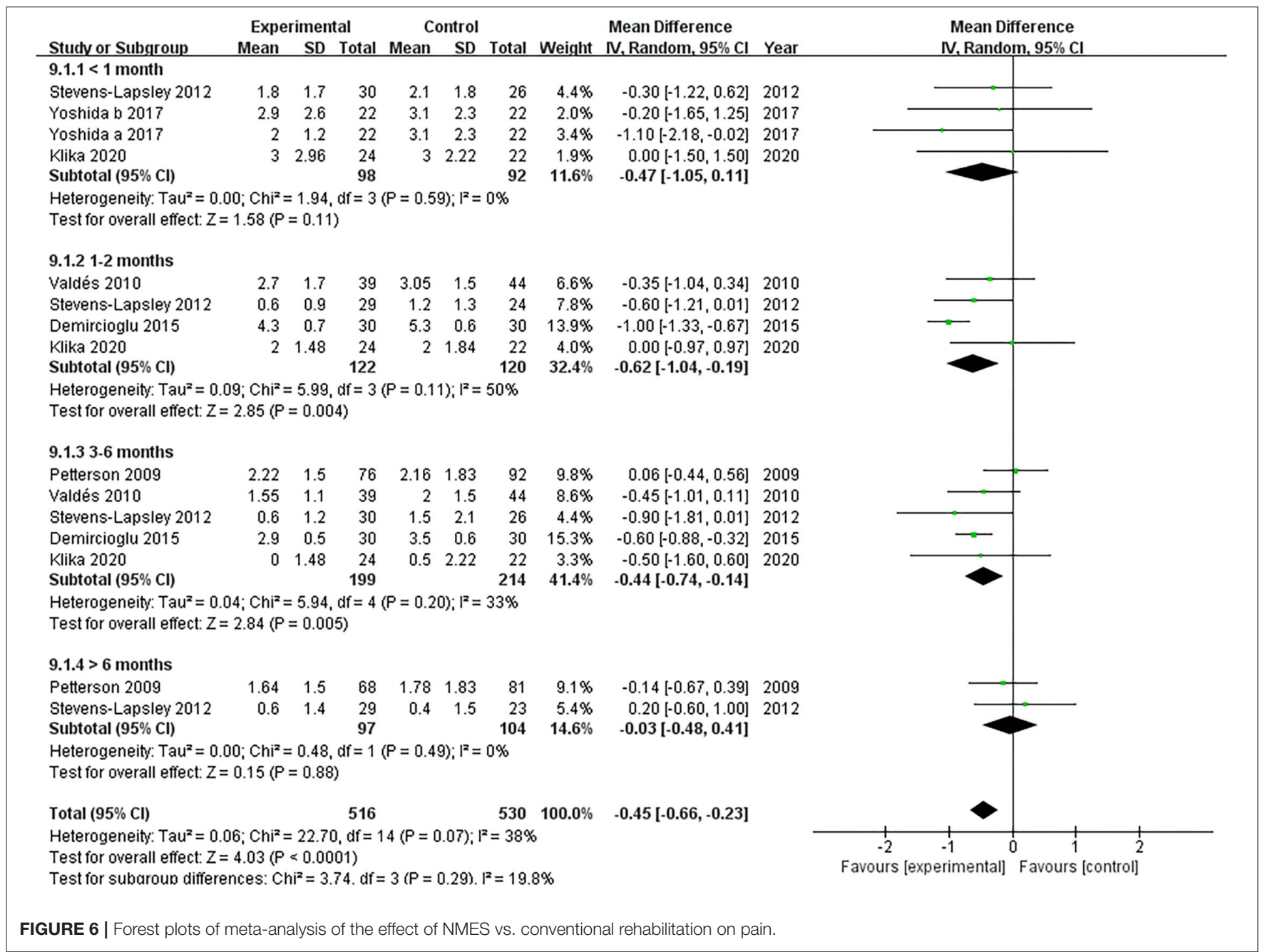




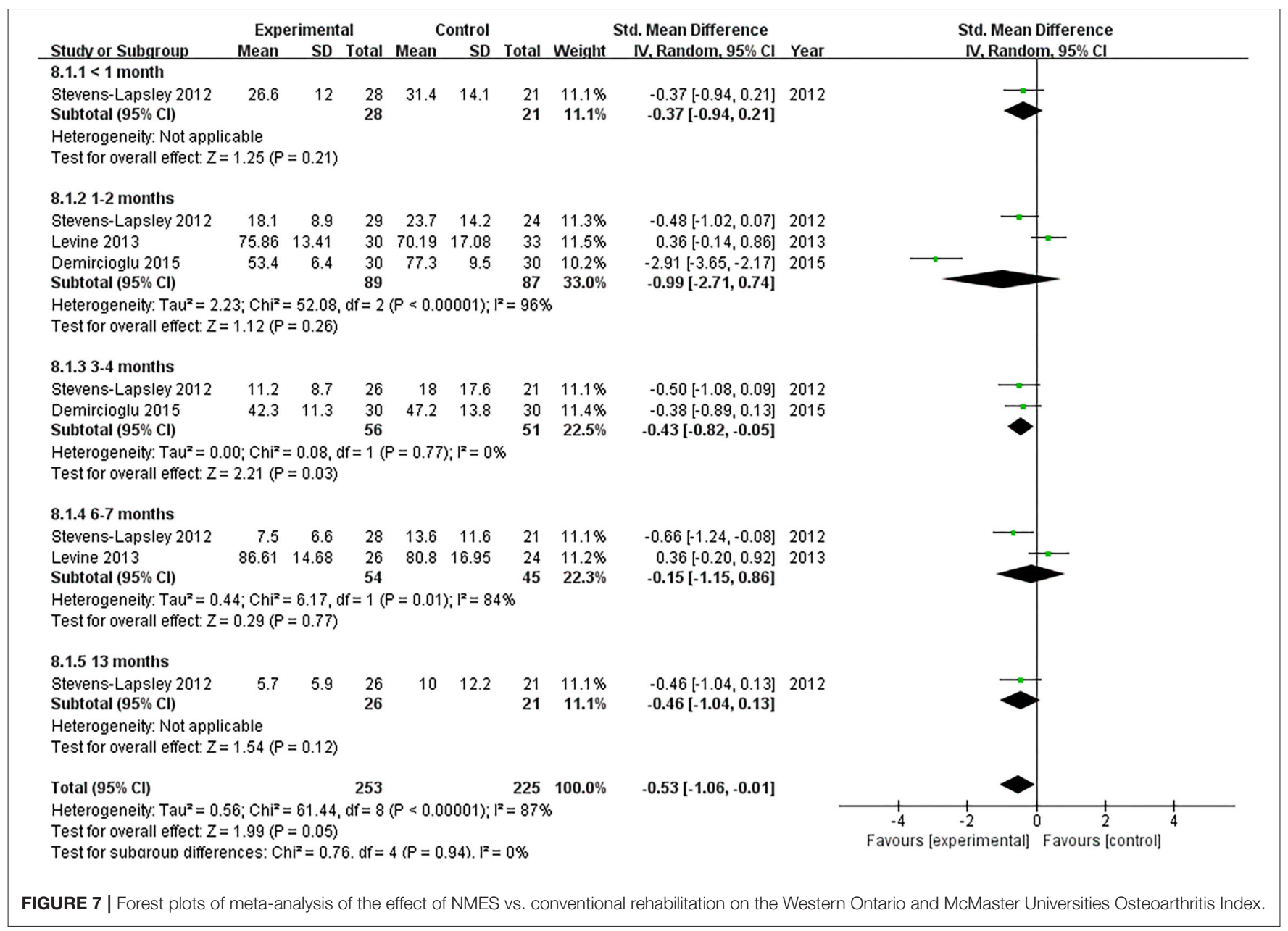

0.01, $I^{2}=0 \%$ ), $1-2$ months (SMD: 0.55; 95\% CI: 0.13-0.97, $P=$ $0.01, I^{2}=7 \%$ ), 3-4 months (SMD: 0.42; 95\% CI: 0.18-0.66, $P<$ $0.01, I^{2}=0 \%$ ), and $12-13$ months (SMD: 0.46; 95\% CI: 0.18-0.74, $\left.P<0.01, I^{2}=0 \%\right)$. There was no significant heterogeneity $\left(I^{2}=\right.$ $0,7,0$, and $0 \%$, respectively). The forest plot of quadriceps muscle strength was shown in Figure 4.

\section{$\mathrm{PCI}$}

Two studies evaluated the PCI $(18,21)$. NMES could not improve PCI between 3 and 6 months or 12 and 13 months after TKA compared with the control group (MD: 0.02; 95\% CI: $-0.02-$ $0.06, P=0.34$; $\mathrm{MD}: 0.01$; $95 \% \mathrm{CI}:-0.03-0.06, P=0.54$; respectively). We found no significant heterogeneity $\left(I^{2}=0 \%\right.$; $I^{2}=8 \%$; respectively). The forest plot of PCI was shown in Figure 5 .

\section{Pain}

Five studies assessed the pain scores during the rehabilitation procedure (19, 22, 38-40). Our pooled analysis comprising 168 patients demonstrated that NMES could not improve pain after TKA compared with the control group (MD: $-0.47 ; 95 \% \mathrm{CI}$ : $-1.05-0.11, P=0.11)$. No significant heterogeneity was found $\left(I^{2}=0 \%\right)$. The NMES significantly improved pain between
1 and 2 months after TKA (MD: -0.62 ; 95\% CI: -1.04 to $-0.19, P=0.004)$. No significant heterogeneity was detected $\left(I^{2}=50 \%\right)$. NMES improved pain between 3 and 6 months after TKA without significant heterogeneity (MD: $-0.44 ; 95 \%$ CI: -0.74 to $\left.-0.14, P=0.005, I^{2}=33 \%\right)$. Besides, no significant difference was found among the groups for more than 6 months (MD: -0.03 ; 95\% CI: $-0.48-0.41, P=0.88$, $\left.I^{2}=0 \%\right)$. The forest plot of the pain score was shown in Figure 6.

\section{WOMAC}

A total of three studies reported the effect of NMES on WOMAC following TKA $(22,37,38)$. Our pooled analysis involving three studies $(22,37,38)$ revealed that NMES could not improve WOMAC between 1 and 2 months (SMD: -0.99 ; 95\% CI: $-2.71-$ $0.74, P=0.26)$. There was significant heterogeneity between the articles $\left(I^{2}=96 \%\right)$. Nevertheless, NMES significantly improved WOMAC between 3 and 4 months after TKA (MD: -0.43 ; 95\% CI: -0.82 to $-0.05, P=0.03)$. No significant heterogeneity was detected among the studies $\left(I^{2}=0 \%\right)$. We failed to find a significant difference in WOMAC between 6 and 7 months (MD: -0.15 ; 95\% CI: $\left.-1.15-0.86, P=0.77, I^{2}=84 \%\right)$. The forest plot of WOMAC was shown in Figure 7. 


\section{TUG}

Six articles documented the effect of NMES on TUG following TKA $(19,22,36-39)$. NMES improve TUG within 1 month after TKA compared with the control group (MD: $-2.23 ; 95 \%$ CI: -3.40 to $-1.07, P=0.0002)$. There was no significant heterogeneity among the articles $\left(I^{2}=3 \%\right)$. However, NMES

\begin{tabular}{|c|c|c|c|c|c|c|c|c|c|c|c|}
\hline \multirow[b]{2}{*}{ Study or Subgroup } & \multicolumn{3}{|c|}{ Experimental } & \multicolumn{2}{|c|}{ Control } & \multirow[b]{2}{*}{ Total } & \multirow{2}{*}{ Weight } & \multirow{2}{*}{$\begin{array}{l}\text { Mean Difference } \\
\text { IV, Random, } 95 \% \mathrm{Cl}\end{array}$} & \multirow[b]{2}{*}{ Year } & \multirow{2}{*}{\multicolumn{2}{|c|}{$\begin{array}{l}\text { Mean Difference } \\
\text { IV, Random, } 95 \% \mathrm{Cl}\end{array}$}} \\
\hline & Mean & SD & Total & Mean & SD & & & & & & \\
\hline \multicolumn{12}{|c|}{ 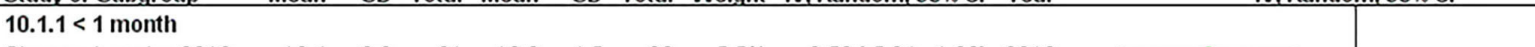 } \\
\hline Stevens-Lapsley 2012 & 10.4 & 3.8 & 31 & 13.9 & 4.5 & 28 & $5.5 \%$ & $-3.50[-5.64,-1.36]$ & 2012 & & \\
\hline Yoshida b 2017 & 10 & 13.1 & 22 & 10.6 & 2.7 & 22 & $1.2 \%$ & $-0.60[-6.19,4.99]$ & 2017 & & \\
\hline Yoshida a 2017 & 8.8 & 1.8 & 22 & 10.6 & 2.7 & 22 & $8.3 \%$ & $-1.80[-3.16,-0.44]$ & 2017 & & \\
\hline Subtotal (95\% Cl) & & & 75 & & & 72 & $15.0 \%$ & $-2.23[-3.40,-1.07]$ & & & \\
\hline \multicolumn{12}{|c|}{$\begin{array}{l}\text { Heterogeneity: } \text { Tau }^{2}=0.05 ; \mathrm{Chi}^{2}=2.07, \mathrm{df}=2(P=0.36) ; \mathrm{I}^{2}=3 \% \\
\text { Test for overall effect: } Z=3.75(P=0.0002)\end{array}$} \\
\hline \multicolumn{12}{|l|}{ 10.1.2 1-2 months } \\
\hline Valdés 2010 & 17 & 7.2 & 39 & 15.2 & 6.5 & 44 & $3.6 \%$ & $1.80[-1.17,4.77]$ & 2010 & & \\
\hline Stevens-Lapsley 2012 & 8 & 2.1 & 31 & 11.3 & 6.8 & 26 & $4.0 \%$ & $-3.30[-6.02,-0.58]$ & 2012 & & \\
\hline Levine 2013 & 13.53 & 4.14 & 30 & 12.21 & 2.83 & 33 & $6.7 \%$ & $1.32[-0.45,3.09]$ & 2013 & & \\
\hline Demircioglu 2015 & 12.8 & 1.9 & 30 & 13.7 & 1.5 & 30 & $10.6 \%$ & $-0.90[-1.77,-0.03]$ & 2015 & & \\
\hline Subtotal (95\% Cl) & & & 130 & & & 133 & $24.8 \%$ & $-0.28[-2.11,1.56]$ & & & \\
\hline \multicolumn{12}{|c|}{$\begin{array}{l}\text { Heterogeneity: } \text { Tau }^{2}=2.40 ; \mathrm{Chi}^{2}=11.27, \mathrm{df}=3(P=0.01) ; \mathrm{l}^{2}=73 \% \\
\text { Test for overall effect: } Z=0.30(P=0.77)\end{array}$} \\
\hline \multicolumn{12}{|l|}{ 10.1.3 3 months } \\
\hline Petterson 2009 & 8.29 & 3.92 & 76 & 8.02 & 3.64 & 92 & $9.3 \%$ & $0.27[-0.88,1.42]$ & 2009 & & \\
\hline Valdés 2010 & 9.7 & 2.8 & 39 & 10.5 & 6.4 & 44 & $5.6 \%$ & $-0.80[-2.89,1.29]$ & 2010 & & \\
\hline Stevens-Lapsley 2012 & 7.5 & 2.2 & 30 & 9.5 & 2.8 & 30 & $8.7 \%$ & $-2.00[-3.27,-0.73]$ & 2012 & & \\
\hline Demircioglu 2015 & 12.3 & 2.1 & 30 & 12.9 & 1.9 & 30 & $9.9 \%$ & $-0.60[-1.61,0.41]$ & 2015 & & \\
\hline Subtotal $(95 \% \mathrm{Cl})$ & & & 175 & & & 196 & $33.5 \%$ & $-0.75[-1.73,0.23]$ & & & \\
\hline \multicolumn{12}{|c|}{$\begin{array}{l}\text { Heterogeneity: } \operatorname{Tau}^{2}=0.54 ; \mathrm{Chi}^{2}=6.76, d f=3(P=0.08) ; \mathrm{I}^{2}=56 \% \\
\text { Test for overall effect: } Z=1.50(P=0.13)\end{array}$} \\
\hline \multicolumn{12}{|l|}{ 10.1.4 6-13 months } \\
\hline Petterson 2009 & 8.07 & 3.92 & 68 & 7.68 & 3.64 & 81 & $8.9 \%$ & $0.39[-0.83,1.61]$ & 2009 & & \\
\hline Stevens-Lapsley 2012 & 7.1 & 2 & 31 & 8.6 & 2.1 & 26 & $9.6 \%$ & $-1.50[-2.57,-0.43]$ & 2012 & & \\
\hline Levine 2013 & 10.64 & 2.88 & 25 & 10.25 & 2.11 & 24 & $8.1 \%$ & $0.39[-1.02,1.80]$ & 2013 & & \\
\hline Subtotal $(95 \% \mathrm{Cl})$ & & & 124 & & & 131 & $26.7 \%$ & $-0.29[-1.60,1.02]$ & & & \\
\hline \multicolumn{12}{|c|}{$\begin{array}{l}\text { Heterogeneity: } \text { Tau }^{2}=0.95 ; \mathrm{Chi}^{2}=6.86, \mathrm{df}=2(P=0.03) ; \mathrm{I}^{2}=71 \% \\
\text { Test for overall effect: } Z=0.43(P=0.67)\end{array}$} \\
\hline Total $(95 \% \mathrm{Cl})$ & & & 504 & & & 532 & $100.0 \%$ & $-0.76[-1.41,-0.10]$ & & & \\
\hline \multicolumn{10}{|c|}{$\begin{array}{l}\text { Heterogeneity: } \operatorname{Tau}^{2}=0.87 ; \mathrm{Chi}^{2}=34.79, \mathrm{df}=13(P=0.0009) ; I^{2}=63 \% \\
\text { Test for overall effect: } Z=2.26(P=0.02) \\
\text { Test for subaroun differences: } \mathrm{Chi}^{2}=6.27 . \mathrm{df}=3(P=0.10) . \mathrm{I}^{2}=52.2 \%\end{array}$} & $\begin{array}{ccc}-4 & -1 & 0 \\
\text { Favours [experimental] }\end{array}$ & Favours [control] \\
\hline
\end{tabular}

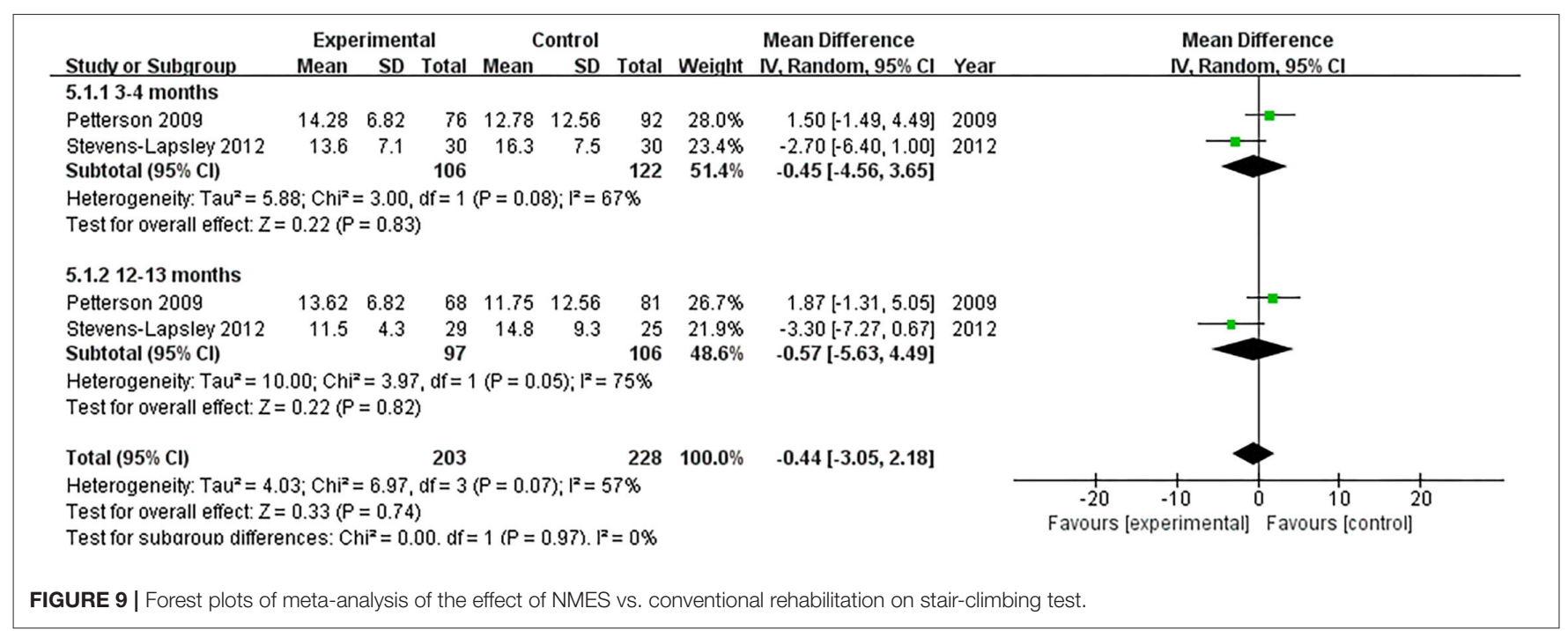


could not improve postoperative TUG between 1 and 2 months, 3 months, or 6 and 13 months (MD $=-0.28,95 \% \mathrm{CI}:-2.11-1.56$, $P=0.77, I^{2}=73 \%$; MD $=-0.75,95 \% \mathrm{CI}:-1.73-0.23, P=0.13$, $I^{2}=56 \% ; \mathrm{MD}=-0.29,95 \% \mathrm{CI}:-1.60-1.02, P=0.67, I^{2}=71 \%$; respectively). The forest plot of TUG was shown in Figure 8.

\section{SCT}

Two RCTs assessed the effect of NMES on SCT following TKA $(19,22)$. NMES could not improve SCT between 3 and 4 months or 12 and 13 months after TKA (MD: -0.45 , 95\% CI: $-4.56-$ 3.65, $P=0.83, I^{2}=67 \%$; MD: $-0.57,95 \% \mathrm{CI}:-5.63-4.49, P=$ $0.82, I^{2}=75 \%$; respectively). The forest plot of SCT was shown in Figure 9.

\section{MWT}

Two studies evaluated the effect of NMES on 3MWT following TKA $(18,21)$. NMES improved 3MWT between 3 and 6 months after TKA compared with the control group (MD: 28.35; 95\% CI: 14.55-42.15, $P<0.0001)$. There was no significant heterogeneity among the studies $\left(I^{2}=0 \%\right)$. However, no significant difference was detected on 3MWT between 12 and 13 months after TKA (MD: 19.06 ; 95\% CI: $-4.84-42.96, P=0.12, I^{2}=65 \%$ ). The forest plot of SCT was shown in Figure 10.

\section{MWT}

Two studies evaluated the effect of NMES on 6MWT following TKA (19, 22). Our pooled analysis involving those two

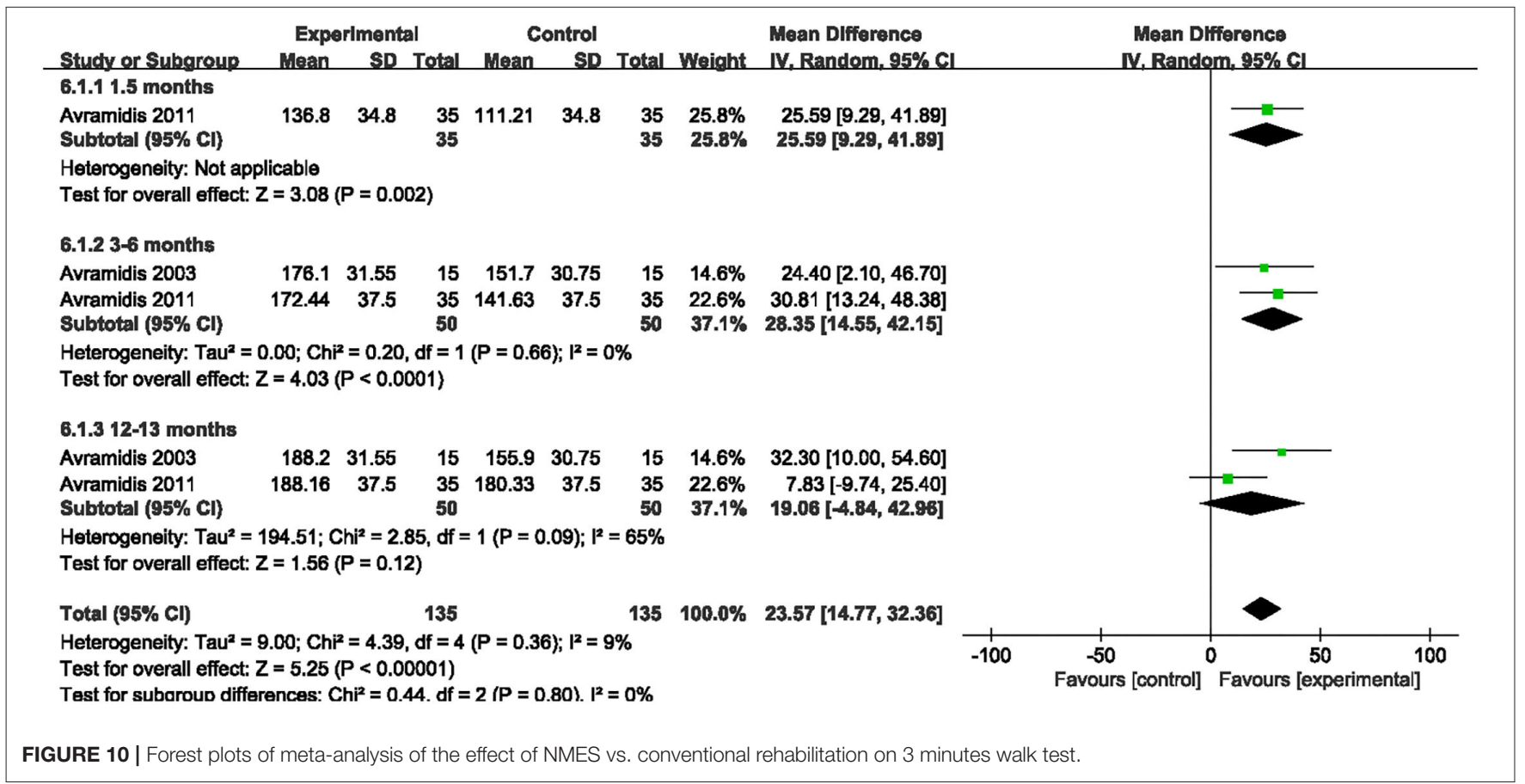

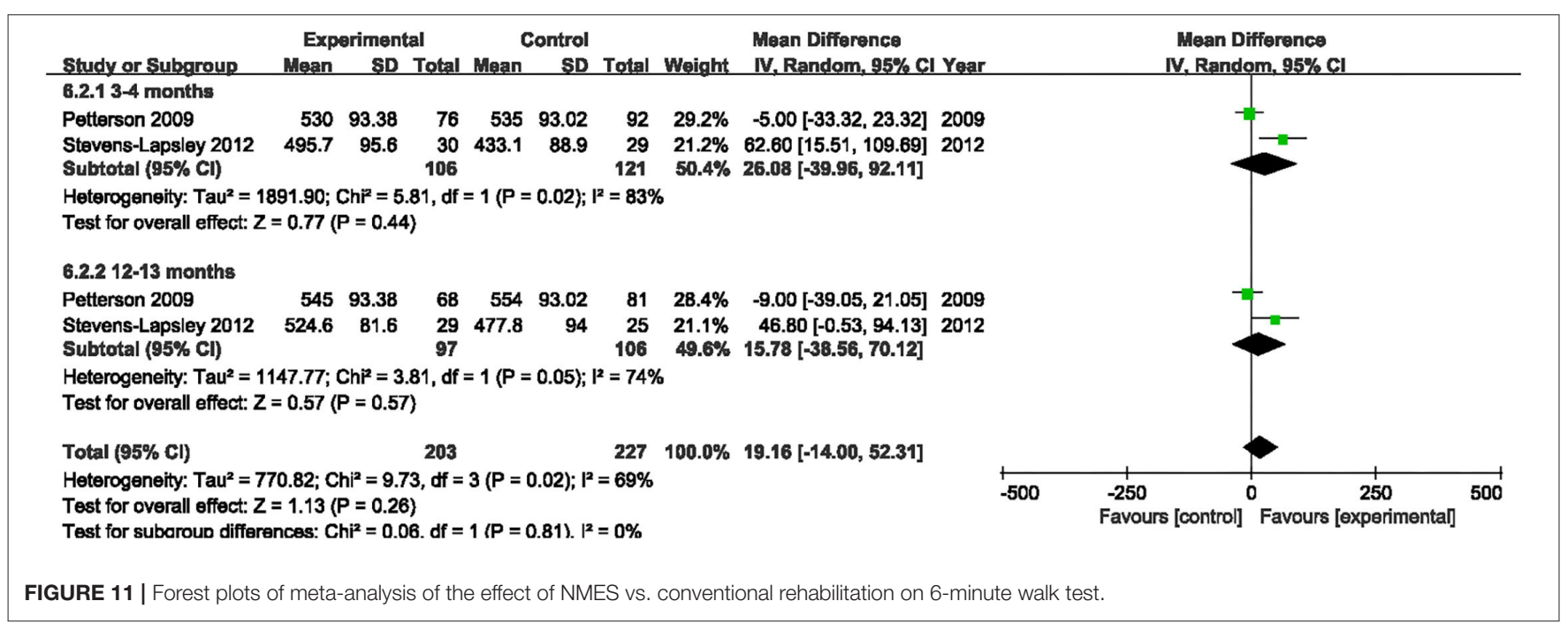




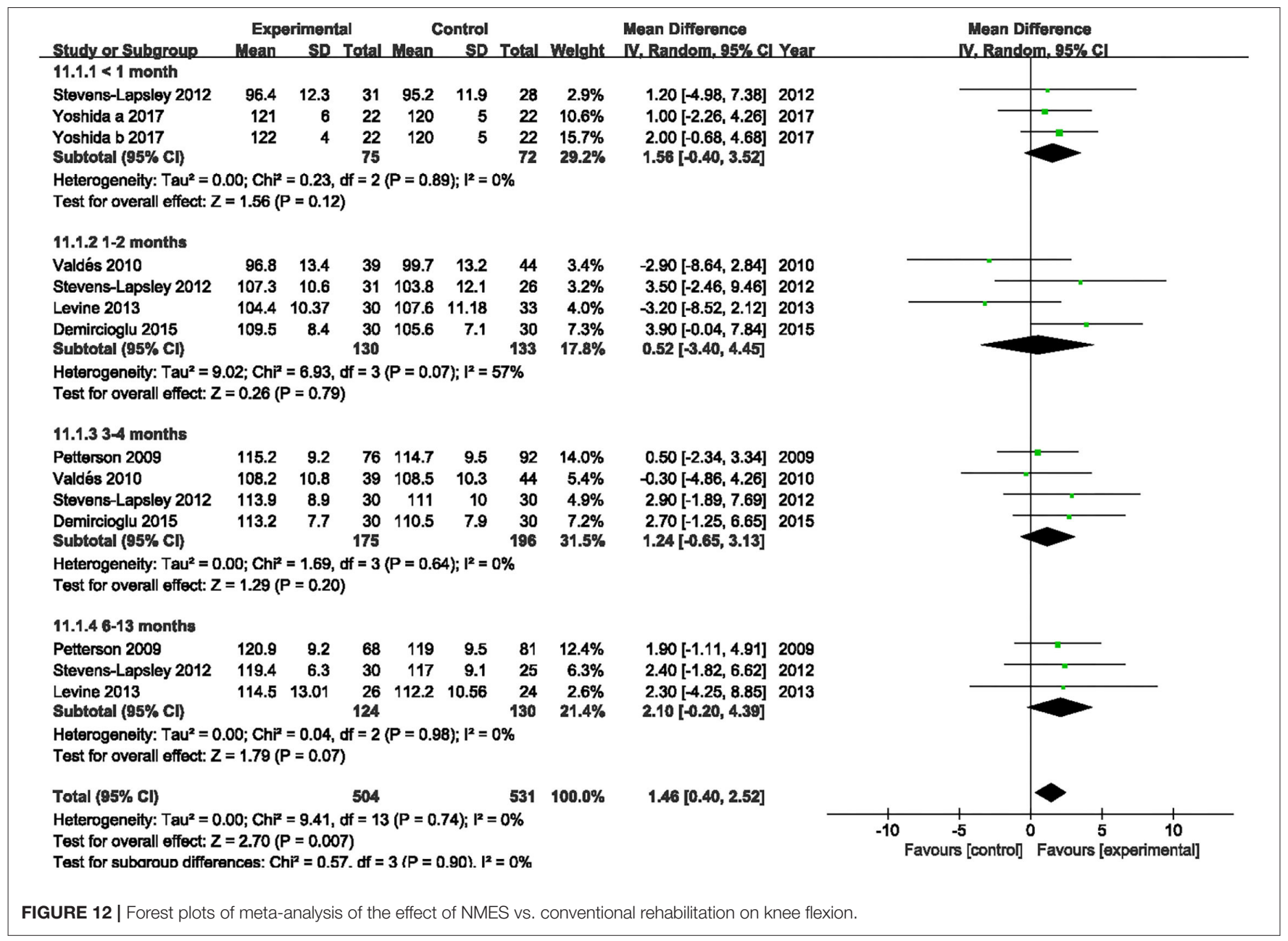

studies $(19,22)$ indicated that NMES could not improve 6MWT between 3 and 4 months or 12 and 13 months after TKA (MD: 26.08, 95\% CI: -39.96-92.11, $P=0.44, I^{2}=$ 83\%; MD: $15.78,95 \%$ CI: $-38.56-70.12, P=0.57, I^{2}=$ $74 \%$; respectively). The forest plot of $6 \mathrm{MWT}$ was shown in Figure 11.

\section{ROM}

Six studies evaluated the effect of NMES on knee flexion following TKA $(19,22,36-39)$. NMES could not improve knee flexion within 1 month, 1 and 2 months, 3 and 4 months, or 6 and 13 months (MD: 1.56, 95\% CI: $-0.40-3.52, P=$ $0.12, I^{2}=0 \% ; \mathrm{MD}=0.52,95 \% \mathrm{CI}:-3.40-4.45, P=0.79, I^{2}$ $=57 \%$; MD: $1.24,95 \% \mathrm{CI}:-0.65-3.13, P=0.20, I^{2}=0 \%$; MD: $2.1095 \%$ CI: $-0.20-4.39, P=0.07$; respectively). The forest plot of knee flexion was shown in Figure 12. Besides, the same six studies evaluated the effect of NMES on knee extension following TKA (19, 22, 36-39). NMES could not improve knee extension within 1 month, 1-2 months, 3-4 months, or 6-13 months (MD: $-0.64,95 \% \mathrm{CI}:-3.86-2.59, P$ $=0.70, I^{2}=81 \% ; \mathrm{MD}=-0.72,95 \% \mathrm{CI}:-1.52-0.08, P=$
0.08, $I^{2}=0 \%$; MD: $-0.21,95 \% \mathrm{CI}:-0.76-0.33, P=0.44$, $I^{2}=0 \%$; MD: -0.01 , 95\% CI: $-1.02-1.00, P=0.98, I^{2}=0 \%$; respectively). The forest plot of knee extension was shown in Figure 13.

\section{SF-36}

Four studies assessed the effect of NMES on SF-36 PCS following TKA $(19,21,22,38)$. NMES could not improve SF-36 PCS after TKA within 3 months, 3-6 months, or more than 6 months (MD: 4.90, 95\% CI: $-0.53-10.34, P=0.08, I^{2}=78 \%$; MD: 3.39, 95\% CI: $-1.91-8.68, P=0.21, I^{2}=87 \%$; $\mathrm{MD}=2.68$, 95\% CI: $\left.-2.23-7.58, P=0.28, I^{2}=90 \%\right)$. The forest plot of SF-36 PCS was shown in Figure 14. The same four studies also assessed the effect of NMES on SF-36 MCS following TKA $(19,21,22,38)$. NMES could not improve SF-36 MCS within 3 months, or more than 6 months (MD: 4.79, 95\% CI: $-1.25-$ 10.82, $P=0.12, I^{2}=81 \%$; MD: 1.12 , 95\% CI: $-0.68-2.93$, $P=0.22, I^{2}=0 \%$, respectively). However, NMES improved SF-36 MCS between 3 and 6 months after TKA (MD: 4.20, 95\% CI: 2.41-5.98, $P<0.01)$. No significant difference was 


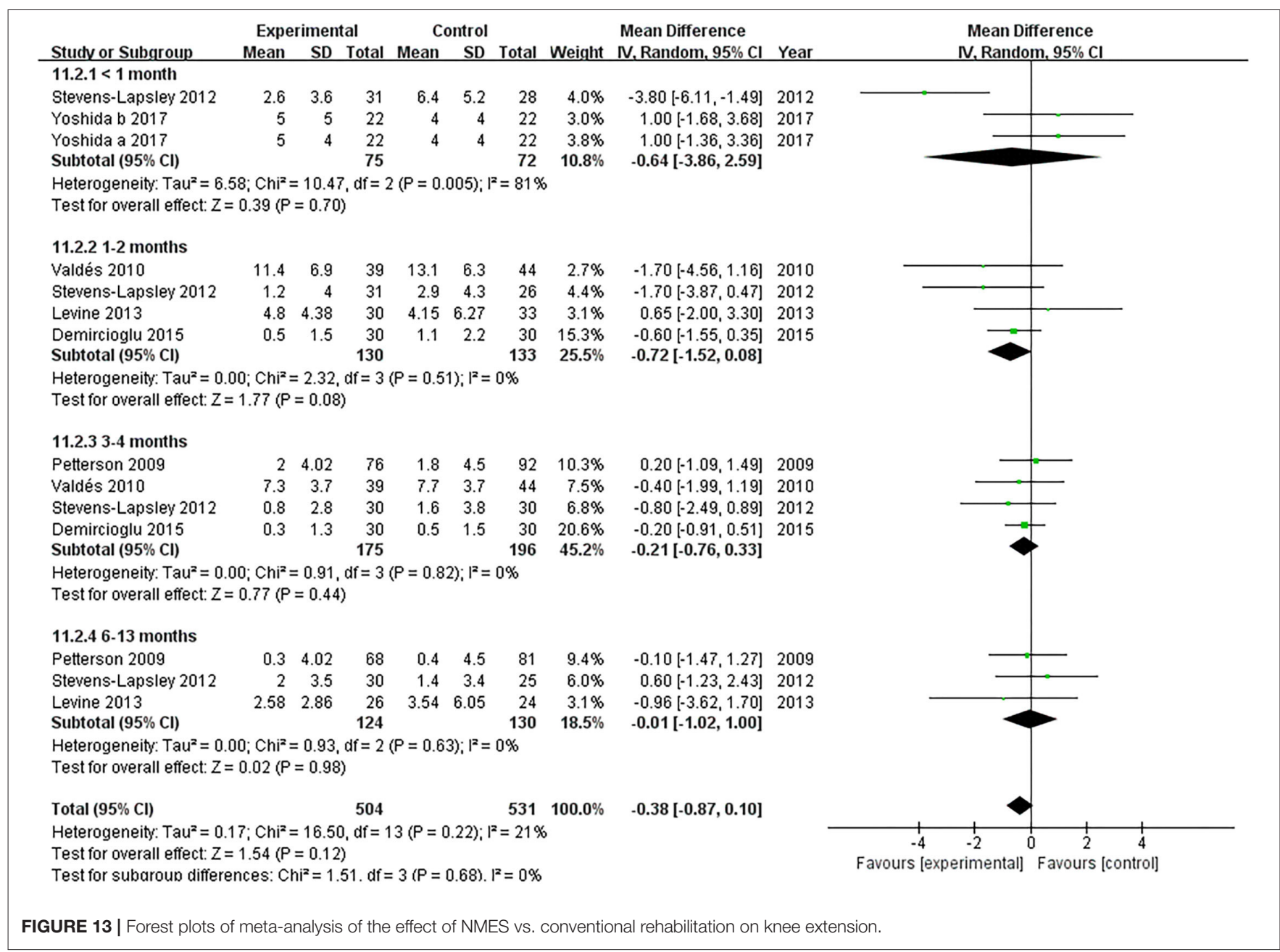

detected $\left(I^{2}=0 \%\right)$. The forest plot of SF-36 MCS was shown in Figure 15.

\section{DISCUSSION}

The purpose of this systematic review and meta-analysis was to explore the effect of NMES on quadriceps muscle strength, pain, and function following TKA. The most important finding of the current study was that postoperative NMES could improve the short-term to long-term quadriceps muscle strength, mid-term pain, and mid-term function following the TKA surgery.

Quadriceps muscle weakness is common following TKA (41). It was reported that $50-60 \%$ quadriceps muscle strength deficits might occur compared with the preoperative levels (23). Besides, quadriceps weakness has been found to increase joint loading and contribute to the progress of osteoarthritis $(42,43)$. It is a crucial goal to restore quadriceps strength for postoperative rehabilitation. Monaghan et al. systematically reviewed relative studies up to 2008. They did not find direct evidence to prove the advantage of NMES on quadriceps muscle strength recovery following TKA by limited (only two) included RCTs (44). Conley et al. conducted a systematic review involving eight RCTs to assess the effect of NMES on quadriceps strength after knee surgery, such as anterior cruciate ligament reconstruction $(n=$ $5)$, TKA $(n=2)$, and meniscectomy $(n=1)(43)$. They revealed that NMES improved the recovery of quadriceps strength after the knee surgery with grade B evidence (43). Due to limited pieces of relevant literature published, some other reviews also failed to examine the effect of NMES on MVIC following TKA $(45,46)$. After including more RCTs that have been published recently, for the first time, we proved that NMES improved quadriceps muscle strength in terms of MVIC after TKA within 1 month, 1-2 months, 3-4 months, and 12-13 months with high-quality evidence.

After including only one published RCT, one previous review failed to explore the pooled effect of NMES on PCI following TKA (45). We found that NMES could not improve PCI after TKA with high-quality evidence.

There was a high risk of severe acute postoperative pain following TKA, undermining the recovery and delaying the fasttrack rehabilitation programs (47). Dabadghav et al. included 28 bilateral TKA patients following osteoarthritis. One knee received NMES plus exercise therapy randomly, and the other 


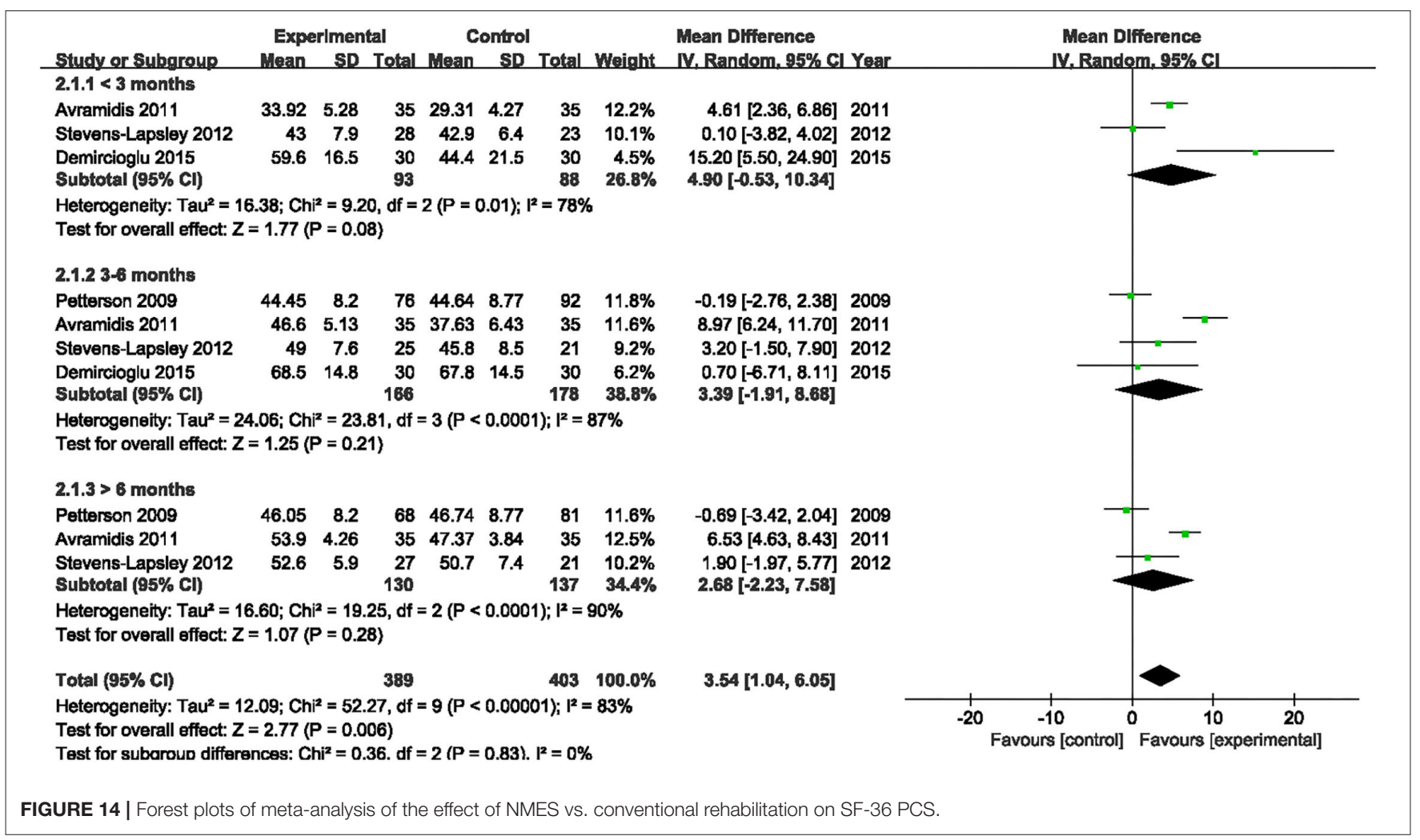

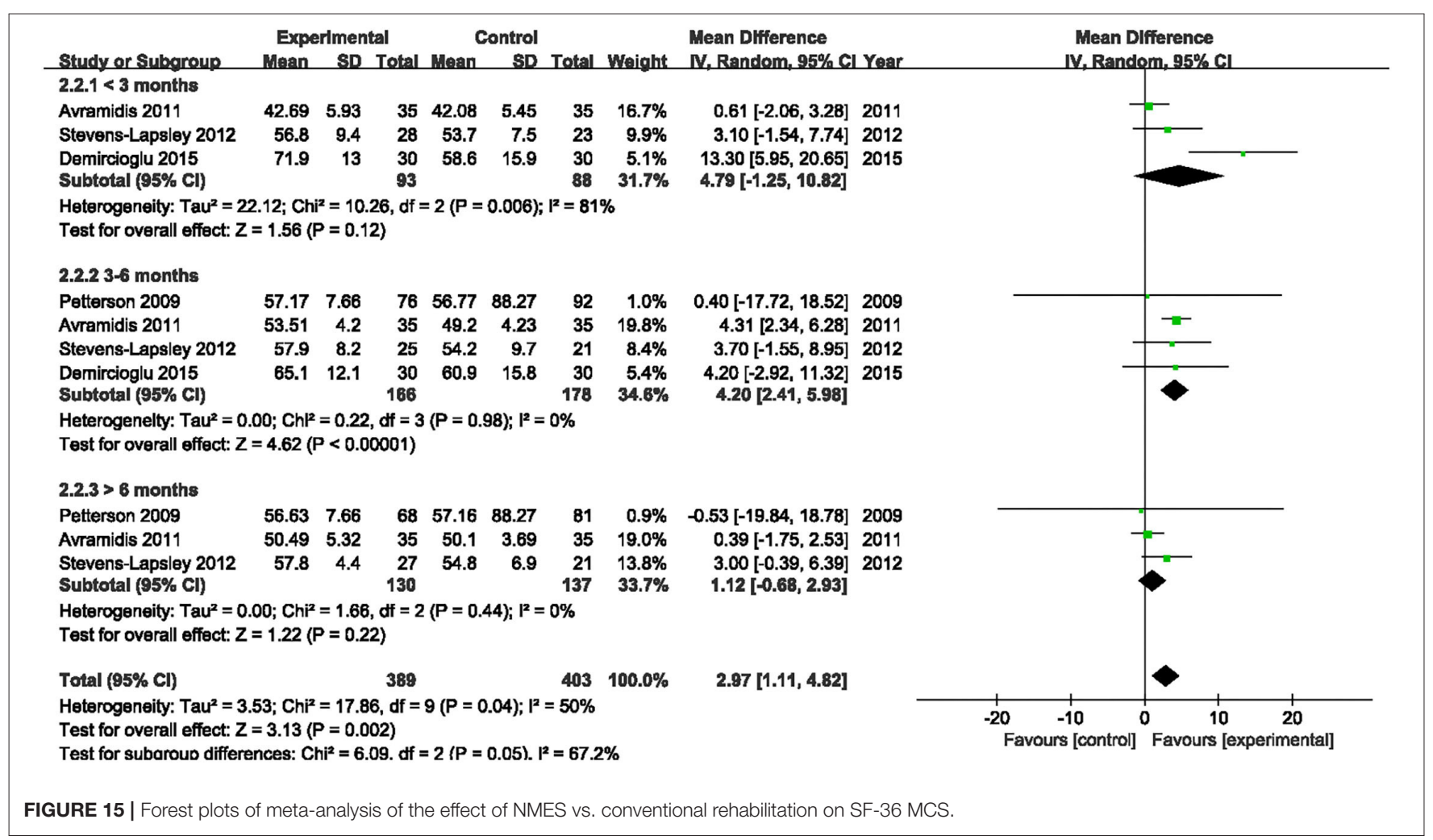

knee received exercise merely. After immediate postsurgical rehabilitation of 7 days, no significant difference between the two knees in terms of pain was detected (48). A matched comparison trial demonstrated that patients using the home-based NMES in the first 6 weeks relieved the pain (49). There was no previous meta-analysis that has evaluated the effect of NMES 
on postoperative pain after TKA. We included five RCTs and found that NMES improved postoperative pain at mid-term (1-2 months and 3-6 months) following TKA. However, the improved differences did not reach the minimal clinically important difference (MCID) in pain (50).

WOMAC is one of the most commonly used questionnaires that assess symptoms and physical function in patients with lower limb osteoarthritis $(51,52)$. Additional NMES therapy of 8 weeks to exercise could not improve the WOMAC in patients with knee OA (53). No previous meta-analysis pooled analyzed the effect of NMES on postoperative function after TKA. We found that NMES improved postoperative WOMAC slightly at mid-term (3-4 months) following TKA with high-quality evidence.

After a matched comparison trial of 6 weeks, patients who used the home-based NMES improved TUG compared with patients in the control group following TKA (49). No previous meta-analysis analyzed the effect of NMES on postoperative TUG following TKA. With high-quality evidence, we found that NMES improved the postoperative TUG at short-term (within 1 month) following TKA. Bruce-Brand et al. found that patients who received home-based NMES for 6 weeks improved the SCT results than patients who received standard care in knee osteoarthritis (54). We discovered that NMES could not improve postoperative SCT with low-quality evidence. The effect of NMES on early TUG (within 1 month) has not been explored in previous literature. The SCT comprises different movements, such as stair ascending, descending, and their transition (55), which may be hard for patients to conduct in the short-term following TKA.

We found that NMES improved postoperative 3MWT at midterm with high-quality evidence but not long-term with lowquality evidence. Another two RCTs reported the effect of NMES on $6 \mathrm{MWT}$ in our study. We found no significant difference between NMES and control groups in terms of 6MWT at midterm or long-term. The previous studies emphasized an excellent correlation between 3MWT and 6MWT. 3MWT was easier to learn and repeat than 6MWT for patients (30). The advantage of NMES was found in terms of 3MWT but not 6MWT. The discrepancy may be related to the limited RCTs.

We detected no advantage of NMES in ROM in the present study, such as knee flexion and extension. Dabadghav et al. included 28 postoperative bilateral TKA patients and randomly allocated one knee to NMES plus exercise, while the other knee received exercise (48). They demonstrated no additional effect in terms of ROM between the two knees from 28 bilateral TKA patients (48). Results from an RCT also showed that NMES could not improve the ROM of the hemiplegic shoulder in patients after stroke (56).

We included four RCTs (involving 344 participants) and found that NMES improved SF-36 MCS at mid-term (3-6 months). No differences were found in terms of MCS at shortterm or long-term. Besides, NMES could not improve PCS at short-term, mid-term, or long-term. A previous meta-analysis confirmed the advantage of NMES on SF-36 MCS at mid-term (12 weeks) by Bistolfi et al. (45). However, they did not explore the effect of NMES on SF-36 at other periods.

Compared with a previous meta-analysis, Bistolfi et al. only included four RCTs and pooled evaluate the effect of NMES on SF-36 merely (45). The evidence to prove the advantage of NMES in TKA was limited. Given the insufficiency of available data for comparison, some other reviews failed to explore the quantized effect of NMES on TKA $(43,44,46,57,58)$. As far as we knew, this was the first systematic review and meta-analysis to comprehensively explore the effect of NMES on quadriceps muscle strength, pain, and function following TKA. However, the differences did not reach the MCID in pain (50). Given the included studies adopt different scales in many essential outcomes, the SMD was used to calculate the total effect of quadriceps muscle strength and WOMAC, which may generate issues with heterogeneity.

The study has several limitations. First, all the included studies failed to achieve the performance bias, which contributed to the main bias of this systematic review and meta-analysis. Second, the programs of NMES were not standardized among the included RCTs, which contributes to the heterogeneity. Third, the sample size was relatively small.

\section{CONCLUSION}

As a supplementary treatment after TKA, postoperative NMES could improve the short-term to long-term quadriceps muscle strength, mid-term pain, and mid-term function following TKA. However, many outcomes failed to achieve statistically meaningful changes and MCID, thus the clinical benefits remained to be confirmed.

\section{DATA AVAILABILITY STATEMENT}

The original contributions presented in the study are included in the article/supplementary material, further inquiries can be directed to the corresponding author.

\section{AUTHOR CONTRIBUTIONS}

BS and LP conceived and designed the analysis. LP and KW search studies from the databases and analyzed data. YZ, YW, and HS participated in the selection of the studies. LP, YW, and HS extract the data. KW, YZ, and BS participated in the quality assessment. LP drafted the manuscript. BS and YZ ensured the accuracy of the data and analysis. All authors have read and approved the manuscript.

\section{FUNDING}

This study was supported through grants from the National Natural Science Foundation of China (81974347) and the Clinical Research Incubation project of West China Hospital, Sichuan University (2018HXFH040).

\section{SUPPLEMENTARY MATERIAL}

The Supplementary Material for this article can be found online at: https://www.frontiersin.org/articles/10.3389/fmed. 2021.779019/full\#supplementary-material 


\section{REFERENCES}

1. Price AJ, Alvand A, Troelsen A, Katz JN, Hooper G, Gray A, et al. Knee replacement. Lancet. (2018) 392:167282. doi: 10.1016/S0140-6736(18)32344-4

2. Skou ST, Roos EM, Laursen MB, Rathleff MS, Arendt-Nielsen L, Simonsen O, et al. A randomized, controlled trial of total knee replacement. $N$ Engl J Med. (2015) 373:1597-606. doi: 10.1056/NEJMoa1505467

3. Mizner RL, Petterson SC, Stevens JE, Vandenborne K, Snyder-Mackler L. Early quadriceps strength loss after total knee arthroplasty. The contributions of muscle atrophy and failure of voluntary muscle activation. J Bone Joint Surg Am. (2005) 87:1047-53. doi: 10.2106/00004623-200505000-00016

4. Li JW, Ma YS, Xiao LK. Postoperative pain management in total knee arthroplasty. Orthopaedic Surg. (2019) 11:755-61. doi: 10.1111/os.12535

5. Bourne RB, Chesworth BM, Davis AM, Mahomed NN, Charron KD. Patient satisfaction after total knee arthroplasty: who is satisfied and who is not? Clin Orthopaedics Related Res. (2010) 468:57-63. doi: 10.1007/s11999-009-1119-9

6. Yue C, Zhang X, Zhu Y, Jia Y, Wang H, Liu Y. Systematic review of three electrical stimulation techniques for rehabilitation after total knee arthroplasty. J Arthroplasty. (2018) 33:2330-7. doi: 10.1016/j.arth.2018.01.070

7. Bohl DD, Li J, Calkins TE, Darrith B, Edmiston TA, Nam D, et al. Physical therapy on postoperative day zero following total knee arthroplasty: a randomized, controlled trial of 394 patients. J Arthroplasty. (2019) 34:S1737.e1. doi: 10.1016/j.arth.2019.02.010

8. Hamilton DF, Beard DJ, Barker KL, Macfarlane GJ, Tuck CE, Stoddart A, et al. Targeting rehabilitation to improve outcomes after total knee arthroplasty in patients at risk of poor outcomes: randomised controlled trial. BMJ. (2020) 371:m3576. doi: 10.1136/bmj.m3576

9. Gotlin RS, Hershkowitz S, Juris PM, Gonzalez EG, Scott WN, Insall JN. Electrical stimulation effect on extensor lag and length of hospital stay after total knee arthroplasty. Arch Phys Med Rehabil. (1994) 75:9579. doi: 10.1016/0003-9993(94)90671-8

10. Hainaut K, Duchateau J. Neuromuscular electrical stimulation and voluntary exercise. Sports Med. (1992) 14:10013. doi: 10.2165/00007256-199214020-00003

11. Enoka RM, Amiridis IG, Duchateau J. Electrical stimulation of muscle: electrophysiology and rehabilitation. Physiology. (2020) 35:40-56. doi: 10.1152/physiol.00015.2019

12. Jones S, Man WD, Gao W, Higginson IJ, Wilcock A, Maddocks M. Neuromuscular electrical stimulation for muscle weakness in adults with advanced disease. Cochrane Database Syst Rev. (2016) 10:Cd009419. doi: 10.1002/14651858.CD009419.pub3

13. Alamer A, Melese H, Nigussie F. Effectiveness of neuromuscular electrical stimulation on post-stroke dysphagia: a systematic review of randomized controlled trials. Clin Intervent Aging. (2020) 15:1521-31. doi: 10.2147/CIA.S262596

14. Carson RG, Buick AR. Neuromuscular electrical stimulationpromoted plasticity of the human brain. J Physiol. (2021) 599:2375-99. doi: 10.1113/JP278298

15. Elbasan B, Akaya KU, Akyuz M, Oskay D. Effects of neuromuscular electrical stimulation and Kinesio Taping applications in children with cerebral palsy on postural control and sitting balance. J Back Musculoskeletal Rehabil. (2018) 31:49-55. doi: 10.3233/BMR-169656

16. Hauger AV, Reiman MP, Bjordal JM, Sheets C, Ledbetter L, Goode AP. Neuromuscular electrical stimulation is effective in strengthening the quadriceps muscle after anterior cruciate ligament surgery. Knee Surg Sports Traumatol Arthroscopy. (2018) 26:399-410. doi: 10.1007/s00167-017-4669-5

17. Miao Q, Qiang JH, Jin YL. Effectiveness of percutaneous neuromuscular electrical stimulation for neck pain relief in patients with cervical spondylosis. Medicine. (2018) 97:e11080. doi: 10.1097/MD.0000000000011080

18. Avramidis K, Strike PW, Taylor PN, Swain ID. Effectiveness of electric stimulation of the vastus medialis muscle in the rehabilitation of patients after total knee arthroplasty. Arch Phys Med Rehabil. (2003) 84:18503. doi: 10.1016/S0003-9993(03)00429-5

19. Petterson SC, Mizner RL, Stevens JE, Raisis L, Bodenstab A, Newcomb W, et al. Improved function from progressive strengthening interventions after total knee arthroplasty: a randomized clinical trial with an imbedded prospective cohort. Arthritis Rheumatism. (2009) 61:174-83. doi: 10.1002/art.24167
20. Laufer Y, Snyder-Mackler L. Response of male and female subjects after total knee arthroplasty to repeated neuromuscular electrical stimulation of the quadriceps femoris muscle. Am J Phys Med Rehabil. (2010) 89:46472. doi: 10.1097/PHM.0b013e3181dd8c0e

21. Avramidis K, Karachalios T, Popotonasios K, Sacorafas D, Papathanasiades AA, Malizos KN. Does electric stimulation of the vastus medialis muscle influence rehabilitation after total knee replacement? Orthopedics. (2011) 34:175. doi: 10.3928/01477447-20110124-06

22. Stevens-Lapsley JE, Balter JE, Wolfe P, Eckhoff DG, Kohrt WM. Early neuromuscular electrical stimulation to improve quadriceps muscle strength after total knee arthroplasty: a randomized controlled trial. Phys Ther. (2012) 92:210-26. doi: 10.2522/ptj.20110124

23. Stevens-Lapsley JE, Balter JE, Wolfe P, Eckhoff DG, Schwartz RS, Schenkman $\mathrm{M}$, et al. Relationship between intensity of quadriceps muscle neuromuscular electrical stimulation and strength recovery after total knee arthroplasty. Phys Ther. (2012) 92:1187-96. doi: 10.2522/ptj.20110479

24. Higgins JPT, Thomas J, Chandler J, Cumpston M, Li T, Page MJ. (editors). Cochrane handbook for systematic reviews of interventions version 6.2 (updated February 2021). Cochrane. (2021). Available online at: www.training. cochrane.org/handbook

25. Liberati A, Altman DG, Tetzlaff J, Mulrow C, Gøtzsche PC, Ioannidis JP, et al. The PRISMA statement for reporting systematic reviews and meta-analyses of studies that evaluate health care interventions: explanation and elaboration. $J$ Clin Epidemiol. (2009) 62:e1-34. doi: 10.1016/j.jclinepi.2009.06.006

26. Meldrum D, Cahalane E, Conroy R, Fitzgerald D, Hardiman O. Maximum voluntary isometric contraction: reference values and clinical application. Amyotrophic Lateral Sclerosis: (2007) 8:47-55. doi: 10.1080/17482960601012491

27. Vllasolli TO, Orovcanec N, Zafirova B, Krasniqi B, Murtezani A, Krasniqi V, et al. Physiological cost index and comfort walking speed in two level lower limb amputees having no vascular disease. Acta Informatica Medica. (2015) 23:12-7. doi: 10.5455/aim.2015.23.12-17

28. Mathias S, Nayak US, Isaacs B. Balance in elderly patients: the "get-up and go" test. Arch Phys Med Rehabil. (1986) 67:387-9.

29. Bennell K, Dobson F, Hinman R. Measures of physical performance assessments: Self-Paced Walk Test (SPWT), Stair Climb Test (SCT), SixMinute Walk Test (6MWT), Chair Stand Test (CST), Timed Up \& Go (TUG), Sock Test, Lift and Carry Test (LCT), and Car Task. Arthritis Care Res. (2011) 63(Suppl. 11):S350-70. doi: 10.1002/acr.20538

30. Iriberri M, Gáldiz JB, Gorostiza A, Ansola P, Jaca C. Comparison of the distances covered during 3 and 6 min walking test. Respir Med. (2002) 96:8126. doi: 10.1053/rmed.2002.1363

31. Southard V, Gallagher R. The 6MWT: will different methods of instruction and measurement affect performance of healthy aging and older adults? $J$ Geriatric Phys Ther. (2013). 36:68-73. doi: 10.1519/JPT.0b013e318264b5e8

32. Laucis NC, Hays RD, Bhattacharyya T. Scoring the SF-36 in orthopaedics: a brief guide. J Bone Joint Surg Am. (2015) 97:1628-34. doi: 10.2106/JBJS.O.00030

33. Matcham F, Scott IC, Rayner L, Hotopf M, Kingsley GH, Norton S, et al. The impact of rheumatoid arthritis on quality-of-life assessed using the SF-36: a systematic review and meta-analysis. Semin Arthritis Rheumatism. (2014) 44:123-30. doi: 10.1016/j.semarthrit.2014.05.001

34. Higgins JP, Altman DG, Gøtzsche PC, Jüni P, Moher D, Oxman AD, et al. The Cochrane Collaboration's tool for assessing risk of bias in randomised trials. BMJ. (2011) 343:d5928. doi: 10.1136/bmj.d5928

35. Takeshima N, Sozu T, Tajika A, Ogawa Y, Hayasaka Y, Furukawa TA. Which is more generalizable, powerful and interpretable in meta-analyses, mean difference or standardized mean difference? BMC Med Res Methodol. (2014) 14:30. doi: 10.1186/1471-2288-14-30

36. Valdés Vilches M, Fernández Ferreras T, Serra Tarragón N, Bujedo Pertejo A, San Segundo Mozo R, Molins Roca J. Feedback and neuromuscular electrical stimulation during an early phase of a rehabilitation programe after total knee arthroplasty. Trauma. (2010) 21:163-8.

37. Levine M, McElroy K, Stakich V, Cicco J. Comparing conventional physical therapy rehabilitation with neuromuscular electrical stimulation after TKA. Orthopedics. (2013) 36:e319-24. doi: 10.3928/01477447-20130222-20

38. Demircioglu DT, Paker N, Erbil E, Bugdayci D, Emre TY. The effect of neuromuscular electrical stimulation on functional status and quality of life 
after knee arthroplasty: a randomized controlled study. J Phys Ther Sci. (2015) 27:2501-6. doi: 10.1589/jpts.27.2501

39. Yoshida Y, Ikuno K, Shomoto K. Comparison of the effect of sensorylevel and conventional motor-level neuromuscular electrical stimulations on quadriceps strength after total knee arthroplasty: a prospective randomized single-blind trial. Arch Phys Med Rehabil. (2017) 98:236470. doi: 10.1016/j.apmr.2017.05.005

40. Klika AK, Yakubek G, Piuzzi N, Calabrese G, Barsoum WK, Higuera CA. Neuromuscular electrical stimulation use after total knee arthroplasty improves early return to function: a randomized trial. J Knee Surg. (2020). doi: 10.1055/s-0040-1713420. [Epub ahead of print].

41. Meier W, Mizner RL, Marcus RL, Dibble LE, Peters C, Lastayo PC. Total knee arthroplasty: muscle impairments, functional limitations, and recommended rehabilitation approaches. J Orthopaedic Sports Phys Ther. (2008) 38:24656. doi: 10.2519/jospt.2008.2715

42. Mikesky AE, Meyer A, Thompson KL. Relationship between quadriceps strength and rate of loading during gait in women. J Orthopaedic Res. (2000) 18:171-5. doi: 10.1002/jor.1100180202

43. Conley CEW, Mattacola CG, Jochimsen KN, Dressler EV, Lattermann C, Howard JS. A comparison of neuromuscular electrical stimulation parameters for postoperative quadriceps strength in patients after knee surgery: a systematic review. Sports Health. (2021) 13:116-27. doi: 10.1177/1941738120964817

44. Monaghan B, Caulfield B, O'Mathúna DP. Surface neuromuscular electrical stimulation for quadriceps strengthening pre and post total knee replacement. Cochrane Database Syst Rev. (2010) 2010:Cd007177. doi: 10.1002/14651858.CD007177.pub2

45. Bistolfi A, Zanovello J, Ferracini R, Allisiardi F, Lioce E, Magistroni E, et al. Evaluation of the effectiveness of neuromuscular electrical stimulation after total knee arthroplasty: a meta-analysis. Am J Phys Med Rehabil. (2018) 97:123-30. doi: 10.1097/PHM.0000000000000847

46. Volpato HB, Szego P, Lenza M, Milan SL, Talerman C, Ferretti M. Femoral quadriceps neuromuscular electrical stimulation after total knee arthroplasty: a systematic review. Einstein. (2016) 14:77-98. doi: 10.1590/S1679-45082015RW3140

47. Grosu I, Lavand'homme P, Thienpont E. Pain after knee arthroplasty: an unresolved issue. Knee Surg Sports Traumatol Arthroscopy. (2014) 22:174458. doi: 10.1007/s00167-013-2750-2

48. Dabadghav R, Potdar A, Patil V, Sancheti P, Shyam A. Additional effect of neuromuscular electrical stimulation on knee extension lag, pain and knee range of motion in immediate postsurgical phase (0-2 weeks) in primary total knee arthroplasty patient. Ann Transl Med. (2019) 7(Suppl 7):S253. doi: 10.21037/atm.2019.09.79

49. Delanois RE, Sodhi N, Acuna A, Doll K, Mont MA, Bhave A. Use of home neuromuscular electrical stimulation in the first 6 weeks improves function and reduces pain after primary total knee arthroplasty: a matched comparison. Ann Transl Med. (2019) 7:S254. doi: 10.21037/atm.2019.09.150

50. Laigaard J, Pedersen C, Rønsbo TN, Mathiesen O, Karlsen APH. Minimal clinically important differences in randomised clinical trials on pain management after total hip and knee arthroplasty: a systematic review. $\mathrm{Br} \mathrm{J}$ Anaesthesia. (2021) 126:1029-37. doi: 10.1016/j.bja.2021.01.021
51. Walker LC, Clement ND, Deehan DJ. Predicting the outcome of total knee arthroplasty using the WOMAC score: a review of the literature. J Knee Surg. (2019) 32:736-41. doi: 10.1055/s-0038-1666866

52. Salaffi F, Leardini G, Canesi B, Mannoni A, Fioravanti A, Caporali R, et al. Reliability and validity of the Western Ontario and McMaster Universities (WOMAC) Osteoarthritis Index in Italian patients with osteoarthritis of the knee. Osteoarthritis Cartilage. (2003) 11:551-60. doi: 10.1016/S1063-4584(03)00089-X

53. Mizusaki Imoto A, Peccin S, Gomes da Silva KN, de Paiva Teixeira LE, Abrahão MI, Fernandes Moça Trevisani V. Effects of neuromuscular electrical stimulation combined with exercises versus an exercise program on the pain and the function in patients with knee osteoarthritis: a randomized controlled trial. BioMed Res Int. (2013) 2013:272018. doi: 10.1155/2013/272018

54. Bruce-Brand RA, Walls RJ, Ong JC, Emerson BS, O’Byrne JM, Moyna NM. Effects of home-based resistance training and neuromuscular electrical stimulation in knee osteoarthritis: a randomized controlled trial. $B M C$ Musculoskeletal Disord. (2012) 13:118. doi: 10.1186/1471-2474-13-118

55. Iijima H, Eguchi $R$, Shimoura $K$, Yamada K, Aoyama $T$, Takahashi M. Transcutaneous electrical nerve stimulation improves stair climbing capacity in people with knee osteoarthritis. Sci Rep. (2020) 10:7294. doi: 10.1038/s41598-020-64176-0

56. de Jong LD, Dijkstra PU, Gerritsen J, Geurts AC, Postema K. Combined arm stretch positioning and neuromuscular electrical stimulation during rehabilitation does not improve range of motion, shoulder pain or function in patients after stroke: a randomised trial. J Physiother. (2013) 59:24554. doi: 10.1016/S1836-9553(13)70201-7

57. Chughtai M, Elmallah RD, Mistry JB, Bhave A, Cherian JJ, McGinn TL, et al. Nonpharmacologic pain management and muscle strengthening following total knee arthroplasty. J Knee Surg. (2016) 29:194-200. doi: 10.1055/s-0035-1569147

58. Kittelson AJ, Stackhouse SK, Stevens-Lapsley JE. Neuromuscular electrical stimulation after total joint arthroplasty: a critical review of recent controlled studies. Euro J Phys Rehabil Med. (2013) 49:909-20.

Conflict of Interest: The authors declare that the research was conducted in the absence of any commercial or financial relationships that could be construed as a potential conflict of interest.

Publisher's Note: All claims expressed in this article are solely those of the authors and do not necessarily represent those of their affiliated organizations, or those of the publisher, the editors and the reviewers. Any product that may be evaluated in this article, or claim that may be made by its manufacturer, is not guaranteed or endorsed by the publisher.

Copyright (C) 2021 Peng, Wang, Zeng, Wu, Si and Shen. This is an open-access article distributed under the terms of the Creative Commons Attribution License (CC $B Y)$. The use, distribution or reproduction in other forums is permitted, provided the original author(s) and the copyright owner(s) are credited and that the original publication in this journal is cited, in accordance with accepted academic practice. No use, distribution or reproduction is permitted which does not comply with these terms. 